\title{
Circadian clocks in crustaceans: identified neuronal and cellular systems
}

\author{
Johannes Strauss, Heinrich Dircksen \\ Department of Zoology, Stockholm University, Svante Arrhenius vag 18A, S-10691 Stockholm, Sweden
}

\section{TABLE OF CONTENTS}

\author{
1. Abstract \\ 2. Introduction: crustacean circadian biology \\ 2.1. Rhythms and circadian phenomena \\ 2.2. Chronobiological systems in Crustacea \\ 2.3. Pacemakers in crustacean circadian systems \\ 3. The cellular basis of crustacean circadian rhythms \\ 3.1. The retina of the eye \\ 3.1.1. Eye pigment migration and its adaptive role \\ 3.1.2. Receptor potential changes of retinular cells in the electroretinogram (ERG) \\ 3.2. Eyestalk systems and mediators of circadian rhythmicity \\ 3.2.1. Red pigment concentrating hormone ( $\mathrm{RPCH})$ \\ 3.2.2. Crustacean hyperglycaemic hormone $(\mathrm{CHH})$ \\ 3.2.3. Pigment-dispersing hormone $(P D H)$ \\ 3.2.4. Serotonin \\ 3.2.5. Melatonin \\ 3.2.6. Further factors with possible effects on circadian rhythmicity \\ 3.3. The caudal photoreceptor of the crayfish terminal abdominal ganglion (CPR) \\ 3.4. Extraretinal brain photoreceptors \\ 3.5. Integration of distributed circadian clock systems and rhythms \\ 4. Comparative aspects of crustacean clocks \\ 4.1. Evolution of circadian pacemakers in arthropods \\ 4.2. Putative clock neurons conserved in crustaceans and insects \\ 4.3. Clock genes in crustaceans \\ 4.3.1. Current knowledge about insect clock genes \\ 4.3.2. Crustacean clock-gene \\ 4.3.3. Crustacean period-gene \\ 5. Perspective \\ 4.3.4. Crustacean cryptochrome-gene \\ 6. Acknowledgements \\ 7. References
}

\section{ABSTRACT}

Circadian rhythms are known for locomotory and reproductive behaviours, and the functioning of sensory organs, nervous structures, metabolism and developmental processes. The mechanisms and cellular bases of control are mainly inferred from circadian phenomenologies, ablation experiments and pharmacological approaches. Cellular systems for regulation summarised here comprise the retina, the eyestalk neuroendocrine X-organ-sinus gland system, several neuropeptides such as red pigment concentrating, hyperglycaemic and pigment-dispersing hormones, and factors such as serotonin and melatonin. No master clock has been identified, but a model of distributed clockwork involves oscillators such as the retinular cells, neurosecretory systems in the optic lobes, putative brain pacemakers, and the caudal photoreceptor. Extraretinal brain photoreceptors mediate entrainment. Comparative analyses of clock neurons and proteins known from insects may allow the identification of candidate clock neurons in crustaceans as putative homologues in the two taxa. Evidence for the existence of "insect-like" intracellular clock proteins and (light sensitive) transcription factors is scarce, but clock-, period-, and cryptochrome-gene products have been localised in the CNS and other organs rendering further investigations into crustacean clockwork very promising.

\section{INTRODUCTION: CRUSTACEAN CIRCADIAN BIOLOGY}

\subsection{Rhythms and circadian phenomena}

Habitats of almost all organisms are exposed to daily changes of light and dark phases, the photoperiod, caused by the earth`s rotational movements. The organisms have to adapt to these natural physical constraints by performing and regulating their activities in a circadian rhythm ("circa dies": approximately a day). Therefore, circadian clocks that regulate internal synchrony and are entrained to external diurnal parameters have evolved in all domains of life $(1,2)$. However, circadian rhythms are only one out of several types of rhythms controlled by distinct well investigated clocks in arthropods, including several 
crustacean species, such as circalunar (3-6), circatidal (6-8), seasonal or circannual rhythms (6, 9). Rhythms shorter than a day are referred to as ultradian. The circadian rhythm has been assumed to be the basic unit of all these rhythms (10), but evidence has been provided that some circadian rhythms at least during certain developmental stages in crustaceans or in distinct sensory neurons result from the coupling of higher frequency ultradian oscillators $(11,12)$ (see 3.3., 3.4., 3.5., 5.).

Crustaceans predominantly inhabit all marine and freshwater environments of the earth, but also live in terrestrial or semi-terrestrial habitats. They usually occur in large numbers and are, thus, of considerable ecological and often economical importance. In this review, the known cellular systems and mediators underlying circadian rhythms in crustaceans will be covered. Rhythmicity as an oecophysiological adaptation involves almost every facet of crustacean biology and comprises developmental, physiological, sensory, and behavioural aspects of several species. Of special importance are photoperiodically controlled rhythmical phenomena in locomotory activity, moulting, and reproduction including the release of eggs or dispersal of larvae, not at last interesting for fisheries in terms of predictions of catches. Rhythmical activities can save energy for the individual animals during their locomotory or reproductive activities, but may under certain circumstances such as during moulting still expose them to extreme stress and vulnerability (13); moulting behaviour is, furthermore, intricately dependent on the relative length of the light and dark phases which defines the progression of seasons (see 14). As many crustaceans live in intertidal habitats, circatidal rhythms play pivotal roles and govern rhythms of locomotory activity, food intake, moulting and reproduction, in addition to circadian rhythms. One extensively investigated species is the shore crab Carcinus maenas which displays reliable patterns of activity as it seeks shelter during low tide and displays major locomotory activity during high tide when water covers its habitat. This activity pattern is retained under constant laboratory conditions as a free-running circatidal rhythm $(6-8,15)$. Circadian rhythms of spontaneous locomotion in the crayfish Procambarus clarkii show bimodal patterns with increased activity both after onset and offset of light, with highest activity after offset of light, a behaviour that persists under constant darkness $(16,17)$. Thus, rhythmic behaviours exploit temporal niches within a fluctuating environment in order to most efficiently support survival and reproduction. Moreover, circadian activity patterns may serve as separation mechanisms for sympatric species, e.g. those using identical food recourses, in that they demand or constitute temporal niches, thereby reducing competition for potentially limited resources (18).

\subsection{Chronobiological systems in Crustacea}

Several crustacean clocks have previously been reviewed with regard to both circadian $(10,19-22)$ and circatidal $(3,4$, $6,8,19)$ rhythms, just to mention only some more recent or extensive works. Whilst ultradian rhythms have been detected in many systems (12), their functional significance has yet to be determined. They are often excluded from further analyses (23), which may well leave aspects of great biological importance unrecognised. We have addressed these phenomena where described.

Although crustaceans are a species-rich and highly diverse group of organisms, concise data on circadian rhythmicity have mainly been obtained from decapod species. Model organisms in many neurobiological studies have been and still are crayfish, mainly the species Procambarus clarkii, Procambarus bouvieri, and Cherax destructor. However, chronobiological studies have involved multiple crustacean species and are preferably comparative. Most common are studies on locomotory patterns, which are perhaps best documented for the shore crab Carcinus maenas (7, 24, 25), crayfish (26), and lobsters (27-30). For C. maenas and species of commercial value such as Homarus americanus, rhythms related to moulting and reproduction have been well documented (31-35). Some data have also been obtained from prawns, e.g. Penaeus (or Litopenaeus) species (36, 37), ditch shrimps (Palaemonetes varians (38), glass shrimps (Palaemonetes pugio; 39) or night shrimps (Processa canaliculata; 40).

Diurnal pigment colour change has been extensively studied in diverse fiddler crabs of the genus $U c a$ and other crustaceans $(41,42)$. As many crustacean species are nocturnal or active during dim or twilight hours, a very interesting aspect of crustacean chronobiology and of considerable oecological importance concerns the diel vertical migration (DVM) performance of many small chiefly planktonic crustacean species in marine and freshwater environments. This is well investigated for marine decapod larvae such as crab zoeae (43), calanid copepods (44), krill species (45-47), and freshwater micro-crustaceans such as cladocerans, e.g. Daphnia species (48). Another aspect is the diel horizontal migration (DHM) more recently studied in nocturnal cave dwelling mysid crustaceans, which show a surprisingly strict regulatory adaptation of certain neurotransmitter expressions to changes in light-dark conditions (49). Circadian rhythmic activities are well documented for locomotory, sensory, and central nervous systems in many crustacean species. The different systems (see Table 1) evidently involve almost all biological functions in crustaceans.

The focus of this review is explicitly on the identified cellular and molecular mechanisms and mediators underlying these circadian rhythms. We will not address the overt phenomena accessible to behavioural observation. Many of these were covered previously by excellent reviews concerning aspects of circatidal, circalunar or circadian rhythms of locomotion $(3,4,6$, $7,15)$, reproduction $(30,50)$, moulting $(9,50)$, and hatching or larval release $(6,51)$. In certain cases, reference will be given only to landmark papers or reviews to provide further detail. Thus, our aim is not to merely summarise well-known adaptations to environmental rhythms, but to outline the known cellular and intercellular mechanisms responsible for these adaptations. We will summarise circadian chronobiological systems of crustaceans and partly use comparative approaches to highlight the commonalities underlying diverse systems. 


\subsection{Pacemakers in crustacean circadian systems}

True endogenous rhythmicity, in general, persists free-running even in absence of entraining environmental cues. It is controlled by internal pacemakers, or clocks, which autonomously control cellular activity levels and thereby regulate physiological and behavioural events in an oscillatory pattern. As in many other animal taxa (52), such oscillators are mainly located in the nervous system of crustaceans $(20,21)$.

The core concept of the biological clock builds upon autonomously oscillating neurons or sets of neurons showing circadian rhythms of activity. If certain rhythmicity is lost after accidental loss or experimental inactivation of the respective cells, thereby showing to be both necessary and sufficient to initiate and maintain that particular rhythmicity, these neurons are termed master clocks, or pacemakers. Pacemakers have been identified in both invertebrates and vertebrates, in which they show endogenous oscillatory activity and can thus give timing information (53). Criteria for a pacemaker are (1) autonomy of circadian oscillatory activity in constant darkness or light conditions, (2) entrainment by external cues to adjust the phase to environmental parameters such as light and temperature, (3) loss of circadian/rhythmic behaviour after ablation of specific tissues or cell groups, (4) reactivation of the rhythmicity after transplantation of the specific cells, and (5) autonomy of circadian activity in vitro of the isolated pacemaker tissue for a reasonable time span $(10,54-56)$.

The neuronal basis of circadian rhythms is considered to be restricted to a specific neural network of identified clock neurons both in arthropods and vertebrates. Especially the use of genetically tractable model organisms has greatly facilitated the identification of molecules, neuronal and glial cells and their interactions that underlie circadian rhythmicity. A biological clock in insects that is located in $\sim 150$ identified neurons has been studied in great detail in the fruit fly Drosophila (57-59). It consists of distinct neuron populations that control morning and evening peaks of locomotory activity, respectively (60-62). In mammals, the pacemaker is located in the suprachiasmatic nucleus of the hypothalamus (63-66). Remarkably, intracellular key regulatory molecules exist as orthologous genes in both invertebrates (Drosophila melanogaster) and vertebrates (Mus musculus), but only very few of these have so far been investigated in crustaceans (see also 4.3.). The circadian pacemaker systems of species in arthropods and vertebrates have been compared extensively in the recent literature, highlighting the function of orthologous genes between the two taxa. Moreover evolutionary conservation has been suggested for the circadian regulation at the molecular level $(52,53,67-70)$ as well as for functional and neuroanatomical similarities (53). This evolutionary conservation of genes and their functions implies that insect clock gene orthologues likely also occur in crustaceans and invites screening for the locations of potential pacemakers by use of molecular criteria. Based upon these phylogenetic considerations, some clock genes as well as the neuropeptide PDH, which is a known clock output in insects, have recently been analysed in crayfish and lobsters (see 4.3.).

In insects and mammals, the circadian pacemakers are located in the brain, associated with the visual system, and are bilaterally coupled (53). A crucial but still unanswered question in crustacean chronobiology is whether circadian rhythmicity is controlled by a single pacemaker or master clock located in the brain, or alternatively by several oscillators of (relative) independence. Ablation of clock neurons in mutant flies or by gene knock-outs, e.g. genetically driven via the introduction of cell death signals, toxins or RNA-interference (RNAi) using Gal4-UAS-system approaches, usually led to complete or partial loss of rhythmicity, which proved the control functions of central pacemakers $(71,72)$. Unfortunately, mutant and genetic (e.g. RNAi) analyses comparable with those in Drosophila have only rarely (in mutant crayfish; 73) or not (yet) been possible in crustaceans. Thus, the evidence for distinct pacemaker locations is mainly derived from experiments performed after ablation of structures accessible with relative ease such as eyestalks, brains and their connectives, and usually in conjunction with locomotor actogram analyses (review: 21).

Several studies have combined organ ablations with pharmacological approaches (74-80), but the definite origin of circadian rhythmicities has so far not been possible to trace down to the cellular level. Crude ablation experiments often led to ambiguous results with respect to pacemaker location $(21,22)$, since ablation or deafferentiation of specific tissues (e.g. eyestalk or brain centres) were able to suppress a given rhythm, but sometimes such rhythms became restored following lesions, as was known for both circadian locomotor and electroretinogram (ERG; see 3.1.2.) rhythms $(81,82)$. Depending on the method of severance (e.g. by squeezing of nerves), this restoration was likely caused by regenerative events via reorganising axons and terminals (83). Experiments showing that brain resections are not sufficient to suppress locomotor rhythmicity in crayfish (84) rendered the existence of a pacemaker exclusively confined to the brain unlikely. The ERG circadian rhythmicity remained intact even in isolated retinae in vitro, which indicated autonomous retinal pacemakers for each eye (23). This conclusion was derived from in vitro experiments with specific ablated tissues, an approach providing important additional sources of information for testing whether tissues or organs have indeed autonomous circadian activities $(23,54,85)$.

As ablation or loss of function and in vitro tissue culturing experiments only allow for crude tissue localisations, the ultimate goal must be to identify the specific neuronal or network origins of the oscillatory activities. Up to the present date, no candidate(s) for distinct neuronal groups forming a single central brain oscillator, or master clock, have been identified conclusively in any crustacean model. Instead, experiments conducted so far have identified several neuronal tissues containing distinctly separate circadian clocks that form complex interactions (10). These exist within the brain (supraoesophageal ganglion) $(10,86)$, the retina of the eye $(10,23)$, the eyestalk $(10)$, and the caudal photoreceptor $(12,87)$. Extracellular electrophysiological recordings from isolated brain-eyestalk preparations have demonstrated circadian multiunit activities and visual evoked potential 
responses of neurons within proto-, deuto- and tritocerebral areas, that showed even some possible connections with the sinus gland. These circadian activities also persisted in isolated brains after eyestalk ablations. Up to the present date, these are the only data giving physiological hints for the existence of endogenous brain pacemakers (88). There are still open questions about how many oscillators exist and how they are coupled in each system or model animal, i.e. how many separate clocks do actually exist in crustaceans. Experimental approaches studying circatidal rhythms by artificially separating tidal cues such as pressure, temperature, and salinity have clearly indicated the presence of multiple, separate clocks in C. maenas which lead to precise spawning times and larval dispersals $(4,89)$. However, the interactions between the oscillators and the integration of their input/output relationships are still not fully understood.

What are the distinct neuronal elements of clocks in crustaceans and how do they relate to those present in other arthropods such as insects? The known mechanisms of crustacean circadian systems and comparisons with insect circadian systems are covered in more depth in sections 3 and 4, respectively. Identified neuronal systems (putatively) responsible for circadian control and their mechanisms will be discussed, and their interactions, as inferred and validated experimentally, are summarised in section 3.5. We argue that the localisation of clock neurons and the identification of clock proteins, peptides and other factors regulating circadian rhythmicity require an integrative approach linking neuroanatomy, molecular physiology and chronobiology.

\section{THE CELLULAR BASIS OF CRUSTACEAN CIRCADIAN RHYTHMS}

\subsection{The retina of the eye}

Among the important phylogenetically common features of the Pancrustacea, which embrace the arthropod groups Insecta and Crustacea (90-92); see also 4.1.), are the retinal elements of the compound eyes, i.e. the ommatidia containing a cuticle-derived cornea and a tetraconate dioptric lens apparatus (Tetraconata concept; 93), eight (in most species) rhabdomic and pigmented sensory cells together with surrounding lateral non-neural pigment cells subserving dynamic adaptations in order to adjust to environmental light conditions by intracellular shielding pigment movements (Figure 1). Involvement of the retina of the eyes as light sensor for circadian regulations can be expected, since close adaptation to the earth`s light/dark phases needs light input detection and fine adjustments during dawn and dusk to changes of the respective illumination conditions for entrainment of rhythmicities, although recent work has attributed a major role in the circadian regulation of locomotion to extraretinal brain photoreceptors in two crayfish species (see 3.4). However, retina ablations caused increases in locomotory activity in crayfish that were otherwise fully light-entrainable and immediately adjusted to phase-shifts in the LD cycle, which indicates an indispensible role of the retinal light sensors (17).

\subsubsection{Eye pigment migration and its adaptive role}

Proper detection of changing illumination requires distinct adaptations with regard to the response sensitivity of the photoreceptors, which is achieved mainly by the functional activities of three sets of cellular elements in the ommatidia of the crustacean retina. The first is a gain setting at the level of the photoreceptors themselves. The second is the movements of the so-called proximal pigments (PP) within the photoreceptors, and the third is the migration of the distal pigments (DP) within the slender lateral primary pigment cells, respectively $(94,95)$. The shielding pigments limit light exposure of the rhabdomic membranes in the photoreceptors during the light phase and optimise photon capture during the dark phase (Figure 1) as has already been shown in the earliest studies (96-98). Accordingly, the absolute sensitivity of the crustacean eye is mainly adjusted by pigment distributions (99). During the light phase (photophase) under sufficient illumination, the PP within the photoreceptors and the DP in the lateral pigment cells become evenly distributed, thereby covering and/or shielding the photoreceptive rhabdom of the retinular sensory cells and large parts of the dioptric apparatus (76). During the dark phase (scotophase), PP and DP concentrate proximally and distally in their respective cell types, thereby enabling (maximal) access of photons to the rhabdom of the photoreceptors. The rhythm of the DP persists in conditions of constant light $(10,97,100)$, as does the rhythm of the PP in constant darkness, whilst pigment migration under controlled conditions is more tightly regulated for the PP in constant darkness than for the DP under constant illumination $(10,96)$. The movement of the PP is dependent on the photoreceptor membrane potential (101) and can be modulated by serotonin, which is apparently also contained within retinular cells themselves (102, 103). In the ditch-fencing crayfish Faxonella clypeata, however, the DP migration is autonomous under both constant dark and light conditions for more than a week (104). The reflecting pigment in the secondary pigment cells or tapetal cells (105) (Figure 1) does not migrate. Interestingly, the diel migrations of the screening pigments also appear to shift the spectral sensitivity of the eyes from more ultraviolet-sensitive during dark-adaptation towards more red-sensitive during light-adaptation in crayfish (106108 ) and in an isopod (Ligia exotica) $(109,110)$. In crayfish, this UV-sensitivity develops only after the first 4 weeks of age of a juvenile; it reaches a maximum after about twelve weeks but decreases slightly towards the adult stage, which, surprisingly, has its maximum eye sensitivity in green light, especially so in the dark-adapted state (108).

Early investigations on pigment migration in isolated eyes have shown DP movements towards the light-adapted state even after dark adaptation (97). While light input is thought to directly control pigment distribution of the PP within the photoreceptors (10), ground breaking early studies on effects of injections of crude extracts into the prawn Palaemonetes (111, 112) and into crayfish (113) have shown that DP movement is regulated by the eyestalk (ganglia) and not by ommatidial cell types themselves. This can easily be tested by measuring the so-called eye-glow (or deep pseudopupil) area, which is produced when light is reflected from the tapetal cells, i.e. when DP (and PP) are in dark-adapted positions (Figure 1). The size of the glow 
area reflects preferably the DP positions, and the eye glow changes with an endogenous circadian rhythm that can be phaseshifted (97, 104, 114-116). Injections of eyestalk extracts into dark-adapted animals at different circadian times elicited glowreducing effects largely dependent upon the injection time of the day, and sinus gland-extirpated animals lose their pseudopupil circadian rhythm towards low amplitude ultradian (2-11hrs) rhythms. It was, therefore, concluded that pigment-dispersing neurosecretions diurnally released from the sinus gland are responsible for the retinal circadian pigment movements (116). In fact, two different neuropeptides with antagonistic effects were isolated from eyestalk extracts and shown to be predominantly involved, termed red-pigment concentrating hormone (RPCH) and pigment-dispersing hormone (PDH). Their eyestalk sources, release sites in the sinus gland, and actions are dealt with in more detail in the following sections (3.2.1. and 3.2.3.). Further details about circadian eye pigment movements and their still largely unclear intracellular mechanisms of cytoplasmic granule movements are provided by comprehensive reviews $(95,117)$.

\subsubsection{Receptor potential changes of retinular cells in the electroretinogram (ERG)}

The sensitivity of the eye shows circadian changes associated with the phases of light and darkness. Electroretinograms (ERG) represent light-evoked summed potentials exclusively of retinula cells (118) that can easily be recorded over long periods of time. However, when the eye is exposed to constant or defined light pulses, the ERG amplitude is modulated in a circadian rhythm. This has been shown for several crustaceans. The circadian behaviour of the ERG also persists under conditions of constant darkness (119), and ERG amplitudes are usually higher during the "expected night" than during the "expected day" (85, 120). This indicates that the intricate adaptations of the retinular cells to low light are driven by an endogenous oscillator. However, it is not clear how this adaptive regulation is achieved at the molecular level and to which extent the ERG rhythms are controlled by neuronal mediators, e.g. neuropeptides and/or neurotransmitters.

There is evidence that the rhythm of photoreceptor sensitivity is autonomously regulated by the retina itself, as has been suggested by work in vitro on isolated eyes (retina and lamina ganglionaris; Figure 2A) $(23,119)$. Whilst intact photoreceptor axons are required for ERG responses, the lamina ganglionaris or other optic ganglia supposedly do not contribute to the recorded ERG (85, 118). Entrainment with reversed light phases for a week also reverses the circadian rhythmicity in vitro (23). Lesion experiments in intact animals have shown that ERG oscillations persist after sectioning of the brain hemiganglia, of the protocerebrum from the deutocerebrum, and of the brain from the remaining nervous system. However, if split-brain resection is done parasagittally, merely the non-operated side remains functional (82). Interestingly, resection of distinct parts of the brain (ipsilateral globuli cells, accessory and olfactory lobes) increases the length of the nocturnal ERG phase, resulting in marked ultrastructural changes such as degranulation in certain sinus gland axon profiles and size reduction of the gland (75, 84). Brain resection or separation of protocerebral hemiganglia leads to desynchronisation of ERG (and locomotory) phases, indicating a neuronal connectivity and synchronisation between the two visual systems (Figure 2B), the phase of which is also largely temperature-insensitive. This indicates that two separate but phase-locked oscillators exist in each hemiganglion that affect the ERG (Figure 2B), and that these have likely a nervous connection to the sinus gland $(75,78,84,121)$. The presence of the sinus gland is actually indispensible for the circadian phase relationships of the ERG rhythms between both eyes, especially prominent under DD conditions (122).

\subsection{Eyestalk systems and mediators of circadian rhythmicity}

The decapod crustacean eyestalk contains visual ganglia or neuropils, i.e. the lamina ganglionaris, the medulla externa, the medulla interna (= lobula), and finally the medulla terminalis, which is in fact part of the lateral protocerebrum of the brain (123-125). The eyestalk proved to be an important source of neuropeptides and small modulators such as serotonin and melatonin involved in circadian regulation, that affect rhythms of locomotion, pigment distribution, and eye sensitivity (10, 20, 21, 95). Most of the neurosecretion within the eyestalk ganglia that is of relevance for circadian rhythmicity appears to be attributed to the well-established neurosecretory X-organ-sinus gland system (XOSG) (126) (e.g. somata cluster A in P. clarkii; 123). The Xorgan somata are located at the anterior lateral cortex of the medulla terminalis proximal to the hemiellipsoid body, and the sinus gland, which is usually situated adjacent to the medial edge between the medullae externa and interna, is formed by axonal endings of XOSG and other neurons that abut upon lacunae around the large ophthalmic artery. From these neurohaemal XOSG terminals several identified neuropeptides are released into the haemolymph, such as red pigment concentrating hormone $(\mathrm{RPCH})$, crustacean hyperglycaemic hormones (CHHs), moult-inhibiting hormone (MIH), vitellogenesis/gonad-inhibiting hormone (VIH/GIH), and mandibular organ-inhibiting hormone (MOIH) (127-133). However, the sinus gland receives additional inputs from other regions of the eyestalk ganglia outside the XOSG and even from the brain (134-136). An important contribution to neurohaemal sinus gland terminals arises from pigment-dispersing hormone-immunoreactive (ir) neurons. These, however, have locations, projection patterns and input regions very different from those of the XOSG neurons (137-141; see also 3.2.3.). Expression and release of neuropeptides from the XOSG, in particular RPCH and CHHs, follow a circadian rhythm as the XOSG system can be driven by retinal illumination (142).

\subsubsection{Red pigment concentrating hormone (RPCH)}

The octapeptide RPCH (pGlu-Leu-Asn-Phe-Ser-Pro-Gly-Trp- $\mathrm{NH}_{2}$ ) was the first invertebrate neuropeptide fully structurally elucidated from eyestalk extracts of Pandalus borealis (143). It shares common features with the insect adipokinetic hormone $(\mathrm{AKH})$ peptide family, viz. a N-terminal pyroglutamate, an aromatic residue at the fourth and a tryptophan at the eighth position (144). This neuropeptide appears to be invariably conserved in decapod crustaceans (145) and has long been known to act antagonistically to PDH by concentrating DP within the retinal pigment cells of the ommatidia (21, 95). Albeit not affecting 
the positions of the PP within the photoreceptors, RPCH enhances the ERG amplitude, i.e. the light sensitivity of the eye, especially in light-adapted animals with an effectivity five-fold over dark-adapted animals irrespective of DP positions during circadian acrophases in the early night $(146,147)$. The clearly dose-dependent effects of RPCH on the ERG, the DP, and even on tegumentary chromatophores were readily blocked by injections of a specific antiserum against an $\mathrm{Y}^{1}$-RPCH analogue (147). RPCH concentrates integumentary chromatophores, again acting antagonistically to PDH (95), and is well known for its strong modulatory activity in the stomatogastric system of Cancer borealis, in which it leads to reversible coupling of separate previously uncoupled identified neuronal oscillators $(148,149)$. Furthermore, it has profound effects on circuitries controlling the crayfish swimmeret rhythm. Although in the latter rhythm RPCH lengthens both the period and the duration of bursts of action potentials, it does not alter the phase relationships (150).

In crayfish and crabs, but not in isopods, RPCH is strongly expressed in the XOSG, and several RPCH-ir interneurons can be distinguished in the optic ganglia and ventral nerve cord (VNC), some with axons running through the protocerebral tract (= optic nerve) $(127,151,152)$. In decapods, up to twenty XOSG neurons project to the sinus gland, which contains the highest amounts of identified $\mathrm{RPCH}$, and from which the peptide is preferably released at night $(20,127,151)$. Furthermore, a distinct group of 8-12 RPCH-neurosecretory neurons next to the lateral medulla externa of crayfish have been traced to extensive branches within this neuropil and in the lamina ganglionaris. Some of their fibres even extend beyond the lamina below the retina, but none of them enters the sinus gland (153). The latter medulla-associated interneurons have endings next to the terminals of the photoreceptors in the lamina. These neurons closely resemble previously identified neurosecretory neurons that exhibit tonic activity in darkness and are inhibited under illumination. It has been argued that these neurons are involved in the feedback control of dark adaptation and/or circadian changes in visual sensitivity (154). Thus, RPCH appears to modulate DP and photoreceptors of the retina via two pathways, via the circulation from the XOSG and via specific interneurons.

RPCH contents in the eyestalks of the fiddler crab Uca pugilator (155) and in two crayfish species change with a circadian rhythm both at the levels of the peptide (U. pugilator, P. clarkii; 156) and the mRNA (crayfish Cherax quadricarinatus; 157). The peptide concentrations rise at the end of the light phase and are highest at the beginning of the dark phase followed by a marked decrease during the dark phase to a trough in the morning (P. clarkii), whilst in C. quadricarinatus the mRNA contents show an acrophase about two hours earlier. The rhythm of RPCH-concentrations is maintained in isolated eyestalks when kept for seven days under LD conditions, although the concentration differences are smaller and the night peaks broader and less well defined than in intact animals (156). These oscillations are indeed autonomous, because they persist under continuous illumination and in constant darkness. Injections of anti-RPCH-serum into the animals caused only slight reductions in the amplitude of the ERG rhythm and only a small lengthening of the circadian period (147). In the crayfish C. quadricarinatus, the mRNA levels clearly show circadian changes at two-fold higher levels in constant darkness but with additional bimodal ultradian components (157). Whether the mentioned RPCH-ir axon terminals at the base of the retina in fact contain and/or are under control of co-localised period-gene products, as has been suggested $(23,157)$ (see also 4.3.3.), deserves further exploration.

$\mathrm{RPCH}$ is, therefore, considered a key molecule in the regulation of the circadian systems of the eye. However, since it does not affect the phase of circadian rhythms, it may act on effectors of rhythmicity only but not on the pacemaker itself (10, 21, 147).

\subsubsection{Crustacean hyperglycaemic hormone (CHH)}

The $\mathrm{CHH}$ peptide subfamily comprises true hyperglycaemic hormones that share sequence similarities with members of a peptide subfamily comprising MIH, VIH and MOIH, especially with regard to the positions of cysteines and the disulphidebridges. However, $\mathrm{CHHs}$ are distinguished when looking at the simpler gene and precursor structures of the latter subfamily peptides, which e.g. lack so-called precursor-related peptides $(131,158,159)$. CHH subfamily peptides usually consist of $72-73$ amino acids (aa), show a sequence similarity exceeding $55 \%$ between species, and have at least eight different established physiological functions $(131,160-162)$. CHHs are produced by XOSG perikarya distinct from those of RPCH neurons (163). These are usually located at the cortex of the medulla terminalis neuropile and are transported to axon terminals in the neurohaemal sinus gland (163). Here, the peptides are released directly into lacunae of the ophthalmic artery. CHHs have relatively species-specific bioactivities and occur in multiple isoforms $(160,164)$. These may be products of up to ten (in shrimps) slightly different genes, but only isoforms originating from alternative splicing processes of $c h h$-genes are differentially distributed in sinus glands and pericardial organs (POs) (165-167). The latter organs contain and release an alternative splice form of $\mathrm{CHH}$ very different from that produced in the XOSG, the so-called POCHH. This peptide is derived from the same chhgene but expressed only in peripheral intrinsic cells of the POs in crabs $(165,168)$ or in so-called thoracic root-cells in lobsters that project to release sites in the POs (169-171). None of the identified POCHHs has a hyperglycaemic effect, and nothing is known about whether they are released rhythmically or do have any function in circadian control.

Carbohydrate metabolism is under circadian regulation with even circatidal components. This is detected as rise and fall in sugar levels in the haemolymph, which depend upon $\mathrm{CHH}$ that itself undergoes circadian changes in concentration (163, 172-176) with the possible exception of deep-sea dwelling crustaceans, since rhythmic diurnal changes in blood sugar are lacking in Norway lobsters, Nephrops norvegicus (177). The centre for the control of oscillating CHH levels has been located in the medulla terminalis of crayfish by ablation experiments, and the haemolymph sugar rhythm can be manipulated by shifting the 
light/dark phase or regionally applied constant darkness: the amplitude diminishes after painting over the eyestalks or totally disappears after painting over eyestalks and rostral cephalothorax, and a slow adaptation with a temporary loss of synchrony occurs in constant darkness. The rhythm is also disrupted by severance of the protocerebral tract connection to the brain (77). Thus, it was proven that the physiological changes in blood sugar levels follow a conspicuous endogenous circadian rhythm entrained by light and dependent upon brain inputs: prior to the onset of the dark phase, $\mathrm{CHH}$ is transported to the sinus gland concomitantly with an increase in XO-perikaryal $\mathrm{CHH}$ production. $\mathrm{CHH}$ is then released into the haemolymph around the onset of the dark phase $(103,163,174)$. This leads to hyperglycaemia about two hours later with rising glucose levels lasting for up to 7 hours, i.e. almost synchronously with phases of high locomotory activity. A second, normally smaller and shorter secretory burst of $\mathrm{CHH}$ release occurs before the onset of light, again leading to hyperglycaemia with a delay of a few hours (163, 174). In the crayfish $P$. clarkii, the CHH contents of eyestalk ganglia show a bimodal circadian rhythm (peaks at 04:00hr and 16-20:00hr in LD, but at $04: 00 \mathrm{hr}$ only in DD) and appear not to precede but to almost coincide with bimodally increasing haemolymph glucose levels (176). Interestingly, this CHH release pattern also coincides well with circadian rhythms of the XOSG neurons, which show highest bursting activity in the evening and during the early night but low level tonic activity during morning and early afternoon hours (Figure 3A) $(21,178)$. When recorded extracellularly from the sinus gland or the XOSG tract, or intracellularly from the perikarya, crayfish XOSG neurons show diurnal spontaneous firing predominantly between dusk and midnight and low activity during the day, whilst other sinus gland innervating neurons (likely PDH-neurons; see below) had activity peaks during the day and low activity at night (179). Diurnally active CHH- (and RPCH-) neurons receive inputs via dendrites branching off the XOSG axon tract (e.g. within the central glomeruli or neuropiles III and VII of the medulla terminalis in P. clarkii; 123) from input terminals of neurons releasing 5HT, biogenic amines (dopamine, octopamine) and enkephalins (see also 3.2.6.) and further inputs from areas next to the olfactory-globular tract (OGT), the likely PDH-ir (see below) optic-globular tract (OPT-GT) which is connected to the so-called diamedullary neuropil adjacent to the medulla and lobula (terminology according to (123), apart from other inputs originating in the brain (77). As judged from pharmacological experiments, serotonin (103, 180, 181), GABA (182), dopamine (183), and several other components (see 178) likely regulate CHH rhythmicity. Furthermore, axonal terminals of brain extraretinal photoreceptors contacting serotonin-ir fibres within the protocerebral bridge of the brain $(184,185)$ may convey circadian information via electron-microscopically proven serotonergic inputs to the XOSG (186). Synchronous bursting patterns of the XOSG neurons are further aided by the strong electrical coupling of most of these neurons $(187,188)$. However, varied experimental approaches in different species led to controversial ideas about the regulatory roles of 5HT, biogenic amines dopamine and octopamine and enkephalins in the functioning of the XOSG (review: 162).

In crayfish and crabs, the CHH-producing XOSG neurosecretory neurons are present shortly before and after hatching and increase in number during the post-larval phases $(189,190)$. A novel source for CHH-like substances has been discovered in the tapetal cells of the ommatidia (Figure 1) of post-embryonic (second stage: PO2) and juvenile crayfish P. clarkii (103). CHH expression in these cells has hitherto never been demonstrated in the adult stage of any crayfish species, but evidence from $\mathrm{CHH}$ release studies using cultured cells in reverse haemolytic plaque assays (181) and most recent Western blot studies in adult $P$. clarkii strongly suggests the presence of a $\mathrm{CHH}$ in retina extracts that is similar in molecular weight to those of the two known isoforms of XOSG CHH in this species $(176,191)$. These cells and the XOSG cells exhibit a clear-cut circadian rhythmicity, as do the supposedly 5HT-ir retinular cells (103). These latter cells in PO2 stages are a few hours earlier in acrophase than the $\mathrm{CHH}$-ir tapetal and XOSG cells, which is suggestive of CHH being controlled by 5HT stimuli in the afternoon. However, this phenomenon appears timely reversed in juveniles, which may indicate that there is no functional connection between these systems (Figure 3B-E) $(22,162,181)$. Daily and circadian changes in relative $\mathrm{CHH}$ abundance in the retina and the eyestalk ganglia are in fact negatively correlated and appear to be under different dual metabolic feedback control by circulating glucose and lactate (176). Whether other newly discovered CHH-ir cells in abdominal segments of shore crab embryos (190) exhibit circadian rhythmicity has not yet been investigated. Interestingly, however, timely surges of contents of CHH in these cells and likely their expression and release patterns appear closely related to larval eclosion and water uptake necessary for eggshell rupture and well known larval hatching rhythms $(31,190,192)$. In juvenile crayfish, a pacemaker system for circadian locomotory behaviour is likely present already from the moment of eclosion (26). However, notably, for hatching larvae released from intertidal or DVM-performing crabs circatidal rhythm components are certainly more important (193-195).

\subsubsection{Pigment dispersing hormone (PDH)}

Pigment dispersing hormone (PDH) is a neurohormone regulating (1) the dispersion of pigment granules in the distal pigment cells of the retina, therefore previously being called light-adapting or distal retinal pigment hormone $(\mathrm{LAH}=\mathrm{DRPH}=$ PDH; 196, 197), (2) the pigment dispersion in integumental chromatophores $(21,95,198)$, and (3) the physiological responses and sensitivity of the compound eye directly $(146,199)$. PDH does not affect granule movements of the PP in retinular photoreceptive cells, but the dispersion of pigments within the primary pigment cells causes additional (protective) shielding of photoreceptors and the dioptric apparatus during the light phase and thereby increases visual acuity. Much less is known about the numerous small-field and wide-field PDH-ir interneurons that occur in all eyestalk ganglia, brains and VNCs of several crustaceans; in fact, for none of these interneurons has any function been identified up to now.

All PDHs are octadecapeptides, and by sequence comparison one can distinguish two types of PDHs, alpha- and betaPDHs, respectively (95). The first discovered as a light-adapting hormone was an alpha-PDH of the prawn Pandalus borealis $(200,201)$ but a somewhat larger diversity is known for the so-called beta-PDHs (202-205); notably, in the shrimp Pandalus jordani, two isoforms of alpha-PDH and one beta-PDH (205), and up to three isoforms of a beta-PDH have been 
detected in the crabs Callinectes sapidus (206), Cancer borealis $(207,208)$ and Cancer productus (140), the shrimps Litopenaeus japonicus (209) and Litopenaeus vannamei (210), the crayfish Orconectes limosus (211), and the lobster H. americanus (207). In the CNS of diverse crustacean species, multiple neurosecretory and interneurons express PDHs (137, 138, 140, 141, 152), but innervation of the sinus gland as known e.g. in the crabs $C$. maenas and $C$. productus, the crayfish $O$. limosus and the lobster H. americanus is restricted to 3-4 neurons, the origin of which is definitely not the medulla terminalis XOSG but perikarya between the medulla interna (lobula) and the medulla terminalis of the eyestalk (Figure 4A,B). These are neurons with T-shaped branches that, together with several other $\mathrm{PDH}$-ir cell groups, form a prominent tract system predominantly in the medulla terminalis, which also contains axons connecting to the brain and to the contralateral eyestalks (arrows in Figure 4A,B) (138, 140, 141). Since the origins of up to three different identified PDH-isoforms in sinus glands are still not clear (140, 211), this problem presents a further complication in the analysis of all these groups of PDH-neurons and for the analysis of possible physiological effects of these hormonally released PDH-isoforms. There is also evidence that these PDH-isoforms are differentially distributed in visual eyestalk ganglia (e.g. the lamina ganglionaris; 140) that are possibly involved in circadian regulation, which but has yet to be demonstrated experimentally. The crustacean PDH-neuron systems are, thus, much more complex than similar neurons in insects that likely express only one single isoform of the orthologous insect pigment dispersing factor PDF (95). For instance, in Drosophila, PDF is a known clock output factor that is expressed in the well-established socalled large and small ventral lateral neurons (4 1- $\mathrm{LN}_{\mathrm{v}} \mathrm{s}$ and $4 \mathrm{~s}-\mathrm{LN}_{\mathrm{v}} \mathrm{s}$ ) next to the medullae (212-214), which are homologues of the so-called PDFMe neurons of several orthopteroid insects $(215,216)$. Putative homologies of the insect PDFMe/LN $\mathrm{V}_{\mathrm{v}}$-type and crustacean lateral medulla-associated (crab C-type) neurons make PDFs and PDHs potential key circadian molecules and PDH likely a suitable marker for clock neurons in crustaceans (see 4.2., cp. 141).

Initial eyestalk ablation experiments had shown that the eyestalk endocrine system is essential for distal retinal pigment movements $(114,196,197)$. PDH even causes pigment dispersion in isolated retinae of the crayfish O. limosus (146) and P. clarkii (199). It was, therefore, presumed that the sinus gland system is the only source of PDH in circadian regulatory activity $(21,116,217)$. Circadian variations have been found in the chromatophorotropic potencies and contents of various eyestalk visual ganglia of the prawn Palaemon paucidens, crayfish $P$. clarkii and the crab U. pugilator $(116,155,218-220)$. In the crab Chasmagnathus granulata, endogenous circadian rhythms of pigment migration exist, with pigments being more dispersed during the day than during the night, and seem to be largely dependent on endogenous beta-PDH release from eyestalk sources. Interestingly, the high sensitivity of melanophores to beta-PDH as displayed in vitro $\left(\mathrm{EC}_{50}=0.18 \mu \mathrm{M}\right)$ is higher during the day than during the night (198). Findings of certain axon profiles in the sinus gland of P. paucidens (221) being depleted in their granule content by prolonged illumination and enriched in dark-adapted animals were later corroborated by the observations in C. maenas that an identified PDH-ir granule type accumulates in distinct sinus gland terminals when crabs were kept for at least three days in constant darkness (137). Recently, however, PDH effects were tested on isolated eyestalks, not just retinae, therefore, including the sinus gland. ERG measurements after perfusion of isolated eyestalks showed significant increases in receptor potential duration but decreases in receptor potential amplitude and retinal pseudopupil area. However, since retinae were not examined after separation from the medullae of the eyestalk, PDH cannot be considered an independent clock component of the retina. Nevertheless, PDH injection in intact animals caused advances of the ERG phase. Thus, this action of the peptide meets well with the criteria for setting the phase of the crayfish ERG (199). It also compares well with the functioning of PDFs in Drosophila and other insects, which regulate or set the phase as well as the period of the circadian rhythm (214, 222, 223). In particular, phase locking between eyestalk ERG rhythms has been attributed to PDH being released from the sinus gland of one light-stimulated eye $(122,224)$. However, as an alternative pathway, large contralateral projections via the protocerebrum exist between eyestalk ganglia of both sides; these large projections are very similar to those of insect PDF-neurons (225-228) and arise from the large PDH-tracts in the medullae terminales of eyestalks formed by PDH-ir C-type cells in decapods (138, 141, 229) (arrows in Figure 4A,B) and PGR1- and PGR3-type medulla-associated PDH-ir neurons in the isopod Oniscus asellus (152).

How are the PDH effects in crustaceans regulated? There is only little evidence that identified PDH- (or a DRPH-) containing neuronal elements themselves show circadian oscillations in crustaceans (219), except for some recently discovered circadian variations in the numbers of a distinct medulla-associated PDH-ir neuron type in the water flea Daphnia magna (230). It was, therefore, suggested that PDH-neurons are regulated by neurotransmitters, which in turn could be appearing rhythmically. Serotonin as one candidate had been shown to disperse black and red pigments in fiddler crabs with a circadian rhythmicity (155, 219, 231-233) (see also 3.2.4.). Eyestalk-less animals even retain a circadian chromatophore and locomotory rhythmicity, which demanded the existence of extra-retinal photoreceptors $(20,234,235)$ that regulate rhythmicity of neurosecretory chromatophorotropins in crustaceans. Most recently, such brain photoreceptors (BPRs) previously known to exist in the crayfish C. destructor (185) were indeed shown to be clearly responsible for circadian locomotory rhythmicity even in retina-ablated, destalked and caudal photoreceptor (CPR)-deafferentiated crayfish. Most interestingly, these authors found evidence that the BPRs are likely contacting directly the large wide-field ascending and decending PDH-interneurons in the brain that may be critical neurons in driving the locomotory rhythms (17) (cp. Figure 4A,B). Whether BPR terminals also contact the contralaterally projecting PDH-ir eyestalk neurons has not yet been established.

\subsubsection{Serotonin}

Serotonin (5-hydroxytryptamin, 5-HT) is a common neurotransmitter in invertebrates and vertebrates; it is synthesised from the amino acid L-tryptophan via the rate-limiting enzyme tryptophan-hydroxylase to 5-hydroxytryptophan that is then 
decarboxylated by an aromatic amino acid decarboxylase. The occurrence of 5-HT in many distinct neurones with in the entire CNS has been described for several crustacean species, including lobster, prawn and crayfish (184, 236-239). A few large neurosecretory VNC-neurons are of special importance for the control of aggressive behaviour (240-242), which in an unnamed species of marbled crayfish Procambarus spec. was recently shown to display circadian rhythmicity, although a dependence upon 5-HT has not yet been analysed in this species (243). Three or more 5-HT receptors are present in the crustacean CNS (244, 245), but only two, 5-HTR 1crust $_{\text {and }}$ 5-HTR 2_Pro (or 5-HTR 1 alpha and 5-HTR 2 beta), have been analysed in more detail and localised in crayfish CNS structures $(246,247)$.

The participation of 5-HT in circadian regulation in crustaceans is well established, and both developmental and daily rhythms have been described in crayfish. 5-HT is already detectable during post-embryonic development in the crayfish retina, eyestalk and brain, and displays circadian fluctuations in 5-HT-concentrations in each tissue, linking the 5-HT system to a pacemaker system $(103,155,248)$. In the lobster $H$. americanus, light-entrainable circadian changes in 5 -HT concentrations have been observed in both the central brain and the eyestalk (249). Changes in the circadian rhythm of 5-HT (and likely its ratelimiting enzyme tryptophan-hydroxylase; 250) during crayfish development according to a 9-12 hr rhythm have been interpreted as (i) being superimposed upon the basic circadian rhythm (248) or (ii) representing an example for an initially ultradian-like rhythmicity of, e.g., the ERG and retinal shielding pigment movements (15min to $4 \mathrm{hrs}$ ), that about 30 days later is being replaced by circadian rhythmicity as has been shown for first instar crayfish $P$. clarkii (22).

Enhancing effects of 5-HT on the amplitude of the ERG have been determined after 5-HT injection into whole animals and 5-HT applications onto isolated eyestalks or retinae. 5-HT affects the positioning of the PP in the retinal photoreceptors, which becomes relocated to the position in the dark-adapted state, and increases the conductance of the photoreceptor membranes (251). These modulatory effects, however, may not only be caused by the changing 5-HT concentrations, but depend on circadian

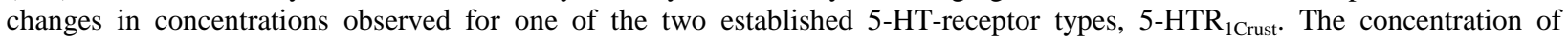
$5-\mathrm{HTR}_{1 \text { crust }}$ in the retina-lamina ganglionaris system is lowest at the end of the dark phase, and reaches its highest concentration at the end of the light phase (252). A similar pattern occurs in both isolated retinae and retina-lamina ganglionaris-complexes, but the isolated retina shows a slight phase advance. This difference may be caused by the higher receptor concentration in the lamina (252). This neuropil is extensively innervated by 5 -HT interneurons $(184,253)$ that form here electron microscopically identified terminals in close apposition to axons of retinular photoreceptor cells, the sensitivity of which is known to be strongly modulated by 5-HT (251). This role of 5-HT has even recently found support by the discovery of pronounced changes in the 5-HT-expression preferably of lamina-innervating neurons that were closely related to artificially elicited near-natural light/darkphase-transitions in cave-dwelling diel horizontally migrating mysid crustaceans (49).

Receptor levels in the crayfish retina and the 5-HT levels in the adult eyestalk occur in similar phase (248), but a reversed phase is seen for 5-HTR receptor fluctuations in the medulla terminalis (252). This finding is particularly puzzling since the established effect of 5-HT-induced CHH release in the eyestalk leading to increased haemolymph glucose levels (103, 180, 181) requires the activation of pharmacologically characterised 5-HTR ${ }_{1}$ - and 5-HTR -like receptors that can be blocked by the 5 -HT-antagonist methysergide $(254,255)$. It is still not clear whether this effect is brought about by 5-HT from neuronal sources in the brain or in the eyestalk, since the eyestalk contains a large number of 5-HT-ir neurons, which can release 5-HT in a paracrine manner depending upon activity (256). 5-HT presumably acts on many 5-HTR lcrust -expressing cells in the eyestalk (253). It appears to be important together with the XOSG for the control of circadian rhythms of retinal sensitivity to light, and likely so already during development $(103,248)$. The $5-\mathrm{HTR}_{1 \text { crust }}$-receptor may, thus, maintain the circadian rhythm in the adult ERG via interneuronal and paracrine modulation of eyestalk neurons by $5-\mathrm{HT}$.

\subsubsection{Melatonin}

Melatonin is a highly conserved molecule universally present in eukaryotes and is an important factor in setting of the mammalian circadian clock responsible for the timing of sleep-wake-cycles $(257,258)$. It always derives in a two-step synthesis from 5-HT being acetylated by the rate-limiting enzyme arylakylamine N-acetyl-transferase (AA-NAT) to N-acetyl-serotonin (NAS) that is then O-methylated by hydroxyindole-O-methyl-transferase (HIOMT) to melatonin.

The presence of serotonin has been investigated in several malacostracan crustaceans, including lobster and crayfish, and documented especially in the visual system (184, 236-238). However, it cannot be excluded that many 5-HT-ir neurons, in addition, express AA-NAT and HIOMT and produce NAS and finally melatonin, respectively, because they had just been immunostained only for their 5-HT precursor. Therefore, it is certainly decisive to identify melatonin in extracts of crustacean nervous systems as has been done first in brains of crayfish and prawns by use of radioimmunoassay (RIA) combined with thinlayer chromatography (259) or later in eyestalks of crabs U. pugilator by RIA combined with high performance liquid chromatography (260). Even in the haemolymph of $N$. norvegicus melatonin was recently identified by liquid chromatography combined with mass spectrometry (LCMS) (261). In crabs and Norway lobsters, melatonin contents clearly showed diurnal variations $(260,261)$. In crabs, melatonin even increased the rate of limb regeneration (260). The other important marker indicating the presence of melatonin is AA-NAT, which has been detected in P. clarkii by a specific radioactive substrate reaction using ${ }^{3} \mathrm{H}$-acetyl-CoA and 5-HT (262). However, in the brain of another crayfish, Pacifastacus leniusculus, only AANAT and its product NAS were found, surprisingly no trace of melatonin or the 5-HT-metabolite 5-hydroxyindole acetic acid (263). 
In the giant freshwater prawn Macrobrachium rosenbergii, AA-NAT contents in the optic lobe increase under continuous light conditions but do not significantly change with a circadian rhythm in LD, whereas melatonin levels show a peak during the day $(15: 00 \mathrm{hr})$ and a nadir during the night $(24: 00 \mathrm{hr})(264,265)$. In $P$. clarkii, levels of AA-NAT and melatonin change with a circadian rhythm, and the highest levels occur at the end of the light phase $(262,266)$. In the crab Uca pugilator, similarly the acrophase of eyestalk melatonin contents lies in the middle of the light phase (13:00hr), whereas an acrophase of AA-NAT contents occurs during the dark phase in the late night (04:00hr). In constant darkness, there are even two melatonin acrophases, one in the middle of the subjective day $(13: 00 \mathrm{hr})$ and another in the late night $(04: 00 \mathrm{hr})$ concurrent with transient increases in AA-NAT contents. In constant light, there is only an acrophase of AA-NAT during the subjective day, but a long acrophase of melatonin (ca. 20hr long) with apparently higher overall levels than during LD and DD (267). In the crab Neohelice granulata, melatonin contents of the optic lobes show two diel peaks of comparable values in the middle of both the light and the dark phases. This diurnal pattern, however, persists only in constant darkness, not under continuous illumination (268). Physiological studies on effects of melatonin in crustaceans are still scarce but apparently coming of age, although the exact cellular (neuronal) sources of melatonin are still unclear. Melatonin is now known to play a role in crustacean antioxidant defence systems and locomotor muscle control in the crab $N$. granulata $(175,269)$. Possible melatonin effects on crayfish antioxidant circadian system still wait to be tested. However, in the two species P. clarkii and Procambarus digueti, the antioxidant systems are known to be very robust in their diel changes (270) and entrain to light phases (271). Especially the glutathione-system in the eyestalk and the brain of P. clarkii exhibits clear-cut circadian rhythmicity $(272,273)$.

With regard to circadian effects in crayfish, melatonin was shown to modulate the ERG amplitude in a dose-dependent manner and depending on the circadian time. Melatonin forces an increase in the ERG amplitude and, thus, has an effect antagonistic to that of PDH. Repeated injections of melatonin synchronize the phase of the ERG (274), but also single doses affect the ERG phase towards an advance or delay depending on the time of injection. Increases in amplitude of the ERG are larger during the subjective day than during the night upon $2 \mathrm{hr}$-interval-injections during a $24 \mathrm{hr}$ cycle. This effect is likely mediated via $\mathrm{MT}_{2}$-like melatonin receptors, as supported by pharmacological application of selective agonist (8-M-PDOT) and antagonist (DH97) (275). Furthermore, melatonin injections can cause reversals of circadian locomotory activity and muscular glucose/lactate cycles depending on the season. Electrophysiology of motoneurons suggested that these effects of melatonin are brought about by neuromodulation, i.e. enhanced synaptic transmission at the neuromuscular junctions of the opener muscle or the extensor muscle of the first walking legs (175).

\subsubsection{Further factors with possible effects on circadian rhythmicity}

Many of the established factors influencing circadian rhythms described before are associated with the eyestalk and contribute to its regulatory functions. In addition, others, especially neuropeptidic factors in circadian control, may well have to be considered in the near future, which is nowadays facilitated by better and faster neuropeptide identifications by LCMS and Maldi-TOF. Interesting but still not identified factors, which were long known from co-localisation studies, are FMRFamiderelated peptides (FaRPs). They are co-localised with PDH in many eyestalk and CNS neurons (138, 229) but the primary structures of the FaRPs in these PDH-neurons are hitherto unknown. A further still unidentified factor is the legendary neurodepressing hormone (NDH). Evidence for the existence of this factor has been obtained from studies in crabs $C$. maenas, crayfish P. bouvieri, and Norway lobsters N. norvegicus. Surgical removal of crab X-organs causing continuous arrhythmic locomotory hyperactivity in crabs, and crayfish eyestalk ganglia extracts and in vitro release experiments from sinus glands eliciting inhibition of crayfish XOSG and motor neuron activities in electrophysiological assays suggested that NDH originates from the XOSG. NDH was, furthermore, found implicated in inhibitory effects on several circadian rhythms $(6,126,276-278)$. However, even the previously suggested and reasonably analysed small neuropeptide nature of NDH (279) was later totally questioned (280). Nonetheless, it would be interesting to examine whether or not NDH is similar or in fact also part of a large family of proven myoinhibitory and neuroinhibitory allatostatin-A-type neuropeptides in crayfish O. limosus (Orcostatins; 281) that occur identically or in many isoforms in several other crustaceans $(208,282-284)$. Another type of NDH may belong to a family of small inhibitory opioid neuropeptides, the enkephalins, which are known to occur in several neurons and fibre networks of the eyestalk ganglia including the medulla terminalis of lobsters (285), crabs (286-288), and crayfish O. limosus (289), and are co-localised with MIH in the crab XOSG-neurons (288). Identified authentic Leu- and Met-enkephalins are known to inhibit the secretory activity of crab and crayfish CHH-neurons and thereby hyperglycaemia, effects that can be antagonised by the opioidreceptor antagonist naloxone $(289,290)$.

\subsection{The caudal photoreceptor of the crayfish terminal abdominal ganglion (CPR).}

A neuron known for a long time to be involved in circadian regulation is the caudal photoreceptor (CPR) of crayfish. It is not an ommatidial photoreceptor but an interneuron directly sensitive to light stimuli with transduction processes taking place within the dendrites $(291,292)$. The CPR is located in anterior lateral positions of the terminal (sixth) abdominal ganglion as a single pair of neurons with large contralateral intraganglionic branchings and ascending projections which merely on that contralateral side extend to terminals next to the antennal and parolfactory lobe neuropils of the brain, on their way giving off short side branches in every VNC neuromere (293); Figure 5. The CPR neurons depolarise upon photic stimulation of the ganglion, but do not adapt over time $(291,292)$. The neuroanatomy of these cells has been detailed to some extent (291, 293295), but full morphological details such as final projection sites and terminal connectivities have not been fully resolved. Some 
additional interneurons located in more anterior abdominal ganglia have been described as photosensitive, but their neuroanatomy and physiological functions are not understood (291).

The CPR is primarily involved in the control of locomotion, regulating light avoidance and evasion behaviours, and can even respond to tactile stimuli or water currents (292). Ganglionectomy of the caudal ganglion affected the circadian rhythm of both the ERG, by inverting its phase in the case of dark-reared animals, and the locomotory activity, which increased after ganglionectomy but remained locked to the established phase (296). Experimental illumination of the caudal ganglion in intact animals affects both the phase of the ERG rhythm and their locomotor activity, and thus revealed the important functional role of the CPR in the coordination of circadian rhythms $(84,297,298)$ (Figure 5). A single illumination of the abdominal ganglion was sufficient to induce phase changes for both locomotory and ERG rhythms, which did not affect the period of the oscillations (84). However, experimental ablation of the CPR did not affect locomotor entrainment, which has helped arguing in favour of entrainment being brought about by an extraretinal light sensor (see 3.4; 16). Illumination of the CPR not only affects the ERG phase but also the ERG receptor potential amplitude and the pseudopupil area $(84,87)$, thereby demonstrating an intricate functional link between the caudal ganglion and the eye. Thus, the CPR has subtle regulatory functions, which may depend upon the length and intensity of light input.

Extracellular electrophysiological recordings have recently shown that the crayfish CPR itself displays circadian rhythms of spontaneous as well as regularly light-induced action potential discharges with only slightly differing periods (24.7hr vs. $24.25 \mathrm{hr})$ but very different acrophases at night time $(21: 40 \mathrm{hr})$ or dawn $(03: 26 \mathrm{hr})$, respectively, in isolated ganglia (12). In addition, ultradian components of ca. $12 \mathrm{~h}$ period were observed for both rhythms and thought to underlie the circadian rhythms. The spontaneous activity of the CPR in isolated ganglia retains a circadian modulation in constant darkness, with highest firing rates at the expected night. The responses to light pulses of identical intensity also vary with a diel rhythmicity especially with regard to a difference in spike rate of up to one order of magnitude. This has been interpreted as a result of circadian changes in the sensitivity of the CPR. Thus, the CPR shows circadian rhythms in activity as well as in sensitivity, the latter being comparable to the intrinsic rhythmicity characteristic for the retinal ERG (12). It is intriguing that both the light sensitivity and the circadian activity reside in the same oscillator neuron. Although these oscillations in the CPR are indeed indicative of spontaneous endogenous activities, the question remains which relevance this photosensor precisely has in circadian regulation (see 3.5.). It will be interesting to analyse the physiological interactions between the CPR and the ERG in more detail.

Further hints about the importance of circadian CPR activity and its regulation within the caudal ganglion have been obtained by pharmacological manipulations: the addition of 5-HT or one of its agonists (8-OH-DPAT) causes a phase shift in both the spontaneous and photoreactive activities (299). This makes 5-HT a candidate for mediating the entrainment effects, although it is not yet known from where the direct 5-HT inputs to the CPR arise or whether the described 5-HTR 1 A receptorimmunoreactive cells in the sixth abdominal ganglion (299) indeed include the CPR. However, the overall level of the serotonin receptor $5-\mathrm{HTR}_{1 \mathrm{~A}}$ was shown to display circadian rhythmicity (12), but the levels of 5-HT and 5-HTR $1 \mathrm{~A}$ are not in phase with each other, leaving still open questions about the functional dynamics underlying oscillations of the CPR and its direct response to 5-HT modulation.

\subsection{Extraretinal brain photoreceptors}

The contribution of photoreceptors located outside the retina to circadian rhythm entrainment has been documented for representatives of several invertebrate taxa (300). In crustaceans, ablation experiments had indicated that photoreceptors other than the retinular cells and the CPR contribute to entrainment of ERG (234) and locomotory rhythms (16), and that entrainment in crayfish lacking retina and lamina ganglionaris persists under monochromatic blue or red light (235, 301). Previously known brain photoreceptors (BPRs) located under the front side of the crayfish cephalothorax (185) have recently been shown to be responsible for the entrainment of locomotory rhythms in a seminal study on the circadian locomotion behaviour of the two crayfish species C. destructor and P. clarkii (17) (cp. Figure 5).

In C. destructor, the BPRs lying on the anterior dorsal surface of the brain consist of clusters of maximally 25 photoreceptive cells. These contain readily visible brownish pigment granules, which greatly facilitate their localisation already in vivo in this species. The pigment granules within the BPR-cell clusters in other crayfish species such as $O$. limosus, P. leniusculus, and P. clarkii are, unfortunately, not as easily visible but recognised only by electron microscopy (302). It is not known whether the pigment granules within BPRs migrate in a similar way, as do those of the PP in the retinular cells (185, 17, 302). BPRs are histamine-ir and express cryptochrome (CRY, see also 4.3.4.), which is presumably the actual photosensitive receptor molecule. The sensory cells of the BPRs project ipsilaterally into specific brain photoreceptor neuropils (BPNs) next to the protocerebral bridge and terminate most likely on PDH-ir and/or 5-HT-ir or tachykinin-like peptide-ir fibres within the BPNs. When ablating retina and CPR thus leaving solely BPRs intact, animals not only maintain their circadian locomotory rhythm even in constant darkness (DD), but also can be entrained to $6 \mathrm{hr}$ phase shifts of LD cycles. However, when more than the retina but entire eyestalks are removed, typical rhythmic responses to lights-on and lights-off are seen with some increased activity in LD, but disappear towards only arrhythmic or continuous activity in DD (17). This provides evidence that the BPRs are necessary and sufficient for light entrainment, but the endogenous rhythm generator likely resides in the eyestalks. Remarkably, the peak locomotor activities after the beginning of the light and dark phases, respectively, correlate with changes in the intensity of PDH-ir fluorescence staining. There are some species-specific differences detectable: in C. destructor, both BPR somata and 
BPNs show an increase in PDH-ir fluorescence intensity with the beginning of the light phase; in $P$. clarkii, the beginnings of both the light and the dark phases correlate with an increase in PDH-ir fluorescence intensity, which precedes the change of illumination. Thus, these fibre stainabilities most likely represent an ongoing oscillatory neuronal activity, which is potentially involved in the initiation of behavioural rhythmicity already at the level of neuronal organisation directly following this sensory receptor. Interesting targets of BPRs in the BPNs are likely the large PDH-ir descending neurons in crayfish (17, 139) and crabs (E-type; 141), and possibly groups of wide-field eyestalk interneurons such as C-type PDH-neurons in crabs (141; Figure 4A,B) likely connecting both eyestalks via the protocerebral tract and the protocerebral bridge.

\subsection{Integration of distributed circadian clock systems and rhythmicities}

Persistent open questions in crustacean chronobiology concern the localisation of the circadian oscillators and their possible interaction. From our present knowledge a complex model begins to emerge, which includes three to four pairs of coupled oscillators such as the retina, the eyestalk XOSG, putative brain pacemakers, the terminal abdominal ganglion (CPR) and paired extraretinal photoreceptors in the brain (BPR), with the latter being involved in light-dependent entrainment. The highly complex circadian functions in various crustaceans thus hitherto appear to contradict a single master clock model. The autonomous oscillators in the XOSG, the caudal photoreceptor, and possibly in the brain, interact within different aspects of rhythm control. While the central players of circadian control have been identified, their mechanistic interactions and the full extent of neural and/or hormonal controls remain to be elucidated. With respect to the systems discussed above, previous research has shown a subtle network of interactions, and the interactions known from studies on crayfish (P. clarkii, P. bouvieri, and C. destructor) are summarised in figure 5 .

The ERG pattern is arguably the most complex circadian oscillation in terms of known regulatory mechanisms, while it has hitherto not been shown to influence other oscillators. The sinus gland affects ERG rhythmicity, most likely by PDH acting on both the retinal DP and photoreceptors directly $(122,217)$. The CPR can set the phase of the ERG rhythm upon prolonged abdominal illumination (298) and adjust it to a $24 \mathrm{hr}$ rhythm (84). Thus, there is obviously no single master oscillator located outside the retina that governs the circadian rhythmicity of the ERG, but several modulatory pathways originating from different oscillators converge onto the retina and determine the different ERG parameters.

Another tightly regulated phenomenon is crayfish locomotion. The retinal light input plays a major role in affecting locomotion: in the crayfish P. clarkii, locomotory activity shows two main peaks closely correlated with the onset and offset of light, respectively. The lights-on-activity peak is initiated by retinal photoreceptors, because animals with ablated retinae lack this activity peak and preferably display the lights-off-activity (16). The period of this activity is supposed to be regulated by the brain, since it is altered after brain resection, while the CPR sets the phase (84). The entrainment of locomotion, however, clearly depends on extraretinal brain photoreceptors (as discussed below in more detail), but there is evidence for a presumed contribution of the sinus gland to entrainment (16).

The XOSG system is itself a proper circadian oscillator (217), yet electrophysiological recordings from single cells do not necessarily show synchronous but differing phases for individual cells, perhaps because subsets are not electrically coupled and express different peptides (179). In crayfish, XOSG outputs affect locomotion (126, 303), ERG amplitude and synchronisation (217), and the retinal pseudopupil (116). However, the neuronal origins of circadian inputs from the brain to the sinus gland as mainly affiliated with PDH or serotonin are still largely unresolved, although such connections have been described neuroanatomically $(304,305)$ and are most likely established by wide-field PDH-ir neurons of the eyestalk and/or the brain (see 3.2.3. and 3.4.).

The CPR affects (visual) sensory and locomotory rhythms. Ablation of the caudal ganglion showed that the CPR is not necessary for entrainment $(16,234,296)$. However, with a typical transitory reaction upon strong light pulses after continuous darkness adaptation (e.g. 2000 lux for 10-30min), the CPR initiates phase shifts in locomotory (296, 303) and ERG rhythms (84, 298). In the cases of its effects on the ERG and the size of the pseudopupil (87), the CPR most likely feeds sensory information into more anteriorly located pacemaker systems via the ascending projections running through the entire VNC into the brain (293), although the postsynaptic interneuronal targets have not been identified (12).

The BPRs, on the other hand, have a clear-cut function in entrainment of locomotory rhythms (17). They relay photic information to BPNs and (indirectly) other brain neuropiles. A closer understanding of which brain (and eyestalk) centres exactly receive this input is necessary to reveal locations of putative central pacemakers and their regulatory roles. Ablation and bisection experiments indicated a role of the protocerebrum, but a distinct clock neuron as demanded by the pacemaker hypothesis has not been identified in the brain. Interaction of the brain with the other oscillators rests, therefore, on circumstantial evidence, but at least a circadian rhythm in spontaneous mass activities has been demonstrated (88). Thus, the origin of circadian rhythmicity in the brain in terms of pacemakers in identified neurons remains elusive. Nevertheless, several studies provided at least evidence for the coupling of ERG rhythms with origin in both eyes via projections through the brain, thus contradicting a single central brain oscillator that would provide synchronising output to both eyes $(78,84,121)$. The underlying coupling mechanism may rely on PDH release only after light stimulation of the extraretinal BPR $(20,87)$ and the CPR $(20,87)$. However, it remains to be proven whether the large PDH-ir brain interneurons and/or group C-type PDH-ir eyestalk neurons (141) are indeed the prime or the only candidates responsible for this coupling between the brain hemispheres and the eyestalk ganglia (Figure 4A,B). 
The discussed interconnections between different oscillators reveal principal organisations of distributed circadian control systems in crayfish. There may be redundant control mechanisms as suggested for circadian locomotor control in $P$. clarkii, which involves several interneurons (86), or in the case of the retina combined with inputs from the sinus gland and the brain, but this issue is so far unresolved and would require experimental co-manipulation of two oscillators to analyse effects on a possible third one. Most applicable up to now appears a network model of distributed interconnected oscillators. This network does not set the rhythm by a single central master clock only but modulates circadian parameters of each oscillator system via phase locking or entrainment. Unfortunately, without deeper knowledge about the neuronal nature and localisation of the central pacemakers and the precise connections between the oscillators, even this network model seems still somewhat premature. An intriguing complementary concept, based initially upon studies on the development of crayfish circadian rhythmicity, derives from the idea that it is the coupling of ultradian rhythms (e.g. of $4 \mathrm{hr}$ period) that most likely under the guidance of sinus gland neurosecretions gives rise to circadian rhythms $(11,116)$, a concept hypothesised similarly for Drosophila (306), and later supported by mathematical modelling in crayfish (307-309). The same concept applies to the ultradian action potential rhythms as elements of a circadian rhythm in the CPR (12). For deeper analyses of the highly complex situation presented here, the aim definitely ought to be the identification of circadian pacemakers in terms of identified neurons or neuron groups. This may be facilitated by comparative studies on arthropod clockwork elements as outlined in the following section.

\section{COMPARATIVE ASPECTS OF CRUSTACEAN CLOCKS}

\subsection{Evolution of circadian pacemakers in arthropods}

Functional studies on crustacean clocks analysing behavioural activities and experimental ablations of specific neuronal tissues or connections have not yet succeeded in clarifying the precise location and cellular identity of pacemaker elements. A suitable approach may, therefore, be to compare circadian clocks and their structural and molecular components known from insects to identify similar systems in crustaceans (141). Shared molecular and neuronal elements can be expected because of the close phylogenetic relationships between insects and crustaceans, which was recently revealed by several phylogenetic studies by use of numerous clearly detectable homologies in neuronal structures and development (reviews: 93, 310). Analyses of morphological, molecular, and neuronal characters supported a novel taxon including insects and crustaceans, the Pancrustacea or Tetraconata $(91,311-315)$.

The insect circadian system has been investigated in tremendous detail and allows for comparisons of neuronal and molecular elements of putative pacemaker neurons, which have been located in similar positions and share similarities in projection patterns in the CNS of several insects (cp. 57, 316-318). Notwithstanding the differences that exist between insect species with regard to the distinct cellular locations and distributions of neuronal clock elements and regulatory clock genes or their products in the brain and/or the optic lobe (57, 316-319), commonalities have perhaps best been documented for the locations of PDH/PDF-ir neurons close to the optic lobes and the role of PDF as a clock output factor (57, 316-318). The bearings on homologies and functional similarity of these neurons are discussed below (see 4.2.).

The homology of optic ganglia and the similar locations of clocks in insect optic lobes and crustacean eyestalk ganglia have already been used in an early study as arguments for a possible homology of clocks in both taxa (320). However, homology cannot be derived from crude tissue localisations alone but requires detailed comparisons of the cellular elements of neurons constituting the presumed pacemakers. These considerations have only recently stimulated investigations dedicated to no longer provide crude tissue associations of pacemakers only but to identify true homologues of clock neurons or clock neuron types in both taxa at the cellular and functional level. In addition, since peptide signalling and the occurrence of clock proteins has even been postulated as a conserved feature of all bilaterian clocks (321), the extensive similarities existing with regard to hitherto identified peptides and clock transcription factors between insects and crustaceans will allow to infer and test comparable functional aspects too. This may be even more successful when structural homologies of putatively involved cell types have already been established, although it cannot be excluded that e.g. orthologous clock genes may regulate oscillatory activities in pacemakers that are not homologues by common descent but were recruited independently in divergent evolutionary lineages. In crayfish, for instance, PDH as one known clock output factor is setting the phase of visual sensitivity (199). This function is clearly comparable with that of orthologous insect PDFs, which are well known to coordinate the phase of circadian rhythmicity in several insects $(214,222,322)$. Since insect PDF-neurons and other brain neurons are well known to express clock genes such as period, timeless and cryptochrome $(57-59,62,323,324)$, and some crustacean neurons were recently found to express similar clock gene products (see 4.3), these neurons should be tested for co-localisations of peptide (or other marker) and clock gene expression, the oscillatory activity of the respective genes and finally for their contributions to clock functions. In the following sections, neuroanatomical and molecular studies are summarised that compare neuronal and molecular characteristics of circadian systems between crustaceans and insects. To identify clock neuron candidates, ultimately circadian changes of clock gene products or clock outputs (neuropeptides and/or neurotransmitters) will have to be demonstrated. These gene products and the expressing tissues or cells can then be linked physiologically to cellular changes and behaviours.

\subsection{Putative clock neurons conserved in crustaceans and insects}


The central clock of most insects is located in the brain or next to optic ganglia of protocerebral origin $(58,59,318)$. Even though the distributed location of circadian functions and the supposed lack of a conspicuous pacemaker in the brain may indicate that crustacean clock structures are significantly different from those in insects, the recent identification of some neurons in lobsters (H. americanus) that are homologous to clock neurons in Drosophila and other insects rather gives hints to expect strikingly similar organisations in insect and crustacean clocks. These PDH-ir neurons of the lobster are very similar to the s$\mathrm{LN}_{\mathrm{v}} \mathrm{s}$ that express the homologous neuropeptide PDF, a clock output of a group of Drosophila pacemakers, which controls the morning bout of locomotory activity $(60,213,214)$, the coordinative 1- $\mathrm{LN}_{\mathrm{v}}$ s of Drosophila (or optic lobe 2-neurons in Phormia terraenovae flies; 325) and the large PDFMe clock neurons of other insects innervating the accessory medulla and the contralateral optic lobes $(213,215,216,318)$.

Classical homology criteria upon which this analysis can build are the position of neuron somata next to the medullae (externa/interna) and the specific qualities of their neuronal connectivities between the visual systems and the brain and their neurochemical characteristics. These considerations define three independent criteria for putative clock neuron homologues in crustaceans. During ontogeny of the lobster, the PDH-ir C-type neurons located next to the medulla and lobula acquire all characters that identify them as potential homologues of these insect PDF-neurons. However, they are organised in three distinct groups (termed C, C' and C'), which makes their individual identification (or exclusion) still somewhat difficult, because either one or several subgroups could likewise be homologous to the insect clock neurons (141). A functional contribution of these neurons to circadian control in the lobster has yet to be demonstrated. As lobsters display circadian locomotory rhythmicity already from the time of hatching, the documented presence of potential PDH-ir clock neurons at this critical developmental time point meets a necessary requirement for considering them as functional in the context of rhythmic control (141). The presence of similar PDH-ir neurons located next to the medulla interna/lobula had also been described in other crustacean species (C. maenas, O. limosus; 138), O. asellus (152), and C. productus (140) partly long before possible clock functions of such neurons could actually be assumed. This highlights the wide distribution of very similar specific PDH-ir cell types among crustaceans, and putative clock neurons of this kind may therefore be well conserved among insects and crustaceans. The recent analysis of similar cell types in the branchiopod species Daphnia magna and D. pulex, which have a highly modified visual system with two separate optic lobe neuropiles within the fused cyclopean eye, adds further weight to such inferences. PDH-ir neurons detected lateral to the medullae of D. magna and D. pulex are fewer in number (3-6 cells per hemisphere) than in the cases of comparable decapod PDH-ir neurons and very similar to the PDF-containing clock neuron types in Drosophila and other insects (230). Nevertheless, a morphological differentiation of distinct PDH-ir neuronal subtypes with exclusively circadian control functions may not occur in all crustacean groups, especially since in most above-mentioned species several additional PDH-ir neurons exist, for which one may not be able to find an insect homologue. Even if clock genes and clock neuronal structures and mediators were very conserved in both taxa, the pacemakers and their circadian functions may still be differing considerably. However, the widespread occurrence among crustacean species of potential pacemaker neurons that similarly express PDH and are located lateral to the medulla allows the promising working hypothesis of such putatively peptidergic clock neurons being conserved irrespective of evolutionary divergence in the Pancrustacea.

When looking at intertidal or subtidal crustaceans we have to take circatidal clocks into consideration. Unfortunately, their neuroanatomy and association with identified chemical mediators is much less studied and only roughly located at the tissue level. In the crab C. maenas and the amphipod Corophium volutator, evidence for the location of circatidal pacemakers in the eyestalk and brain has been provided based on eyestalk extirpation and selective cooling experiments of the nervous system (74, 326). For the crab Sesarma hematocheir, embryonic hatching is tightly controlled in a circatidal manner correlated with nocturnal high tides and is self-sustaining under constant darkness (327). In search for the neuronal control of hatching, deafferentiation experiments have shown that mainly the medulla terminalis of the eyestalk is responsible, as the hatching process and its synchrony were consistently disrupted. Disrupted hatching behaviour clearly indicated timing signals from the medulla terminalis, and thus the location of a pacemaker therein (193). At present, we can only speculate that this circatidal clock relates to known circadian pacemakers, but investigations on its localisation and homology to circadian systems have very promising research prospects.

\subsection{Clock genes in crustaceans}

\subsubsection{Current knowledge about insect clock genes}

In Drosophila, seven clock genes have been identified as essential for intact circadian rhythmicity: period, timeless, clock, cycle, double-time, shaggy and vrille, as well as cryptochrome (58). The basis of oscillatory pacemaker activity is the oscillatory activity of gene expression $(67,328)$, and these clock genes form interactive feedback loops regulating their own transcriptional activity, which results in successive expression and repression $(55,329)$. Clock (CLK) and Cycle (CYC) proteins form heterodimers, which bind to regulatory sequences of period- and timeless-genes and initiate their expression. Period (PER) and Timeless (TIM) proteins in turn form a heterodimer in association with Shaggy (SGG) and Double-time (DBT). This complex enters the nucleus and binds to CLK-CYC, causing this heterodimer to dissociate from the regulatory sequences and thereby stop PER and TIM expression. Cryptochrome (CRY) can regulate this feedback loop by binding to TIM. Therefore, and induced by illumination, CRY undergoes a conformational change which ultimately leads to the degradation of TIM and the interruption of the dimerisation of PER and TIM. Thus, CRY can adapt the transitional oscillations of PER and TIM interactions to changes in light-dark phases. In a second feedback loop, CLK-CYC dimers regulate expression of Vrille (VRI). An 
activational factor (Act) initiates constitutively the expression of CLK, allowing the maintenance of CLK cycling which ultimately integrates the first feedback loop and the continued activation of PER/TIM (319). The ventral lateral $\left(\mathrm{LN}_{\mathrm{v}} \mathrm{s}\right)$ and the dorsal neurons (DNs) of the Drosophila clock circuitry all express period- and timeless-genes (58). Of the seven clock genes identified in insects, only three genes (clock, period and cryptochrome) or their products have up to the present date been detected in crustaceans. They occur in distinct eyestalk neurons or the BPR, but neither in retinal cells nor in the CPR. In search for clock neurons which qualify as pacemakers, not just gene expression profiling of specific neurons is important but also the physiological demonstration of the actual molecular oscillation of transcription, translation and/or phosphorylation of the molecular key players. The present knowledge about crustacean clock genes and their products is scarce with respect to distribution, oscillatory activity, and chronobiological function. Detailed circadian studies may be required for every single clock gene to ensure that cycling of its mRNA or the derived protein(s) is actually functionally necessary.

\subsubsection{Crustacean clock -gene}

In crustaceans, a clock gene product clearly homologous to insect Clock (CLK) is so far the first and the only properly identified circadian clock protein. It has been fully sequenced only in the one single case of the precursor for a CLK protein of the prawn M. rosenbergii (330), termed Mar-Clk. When compared with CLK proteins of insects, Mar-CLK shows considerable sequence identity, in fact, highest to Drosophila CLK ( 35\%) and particularly high with regard to the functionally important domains, the DNA-binding basic helix-loop-helix (bHLH; more than 64\%) and PER-ARNT-SIM (PAS) A and B protein binding domains (more than $44 \%$ and more than $80 \%$, respectively). Interestingly, it contains an exceptionally long glutamine-rich region at the C-terminus well known, in insects, as a necessary domain to activate so-called E-boxes of six conserved nucleotides 5 -upstream of period- and timeless-genes. Mar-CLK mRNA is present in all tissues tested (brain, thoracic ganglia, eyestalk, gill, hepatopancreas, ovary, and muscle) and not limited to the brain or CNS. The CLK mRNA is not expressed in a circadian rhythm, neither in thoracic ganglia nor in eyestalk nervous tissue, as studied by semi-quantitative RT-PCR, but possible rhythmicity has not yet been tested at the protein level. Eyestalk-ablated animals show an increase in clock-gene expression in the CNS including the brain, although the putative CLK-expressing neurons involved have not yet been identified. This CLK-upregulating effect has been interpreted as being the result of the absence of light input, since intact animals kept in constant darkness conditions show a comparable increase within three days (330). These findings again underscore the importance of the eyestalk in circadian regulation, although an effect of (putatively neuronal) CLK in the eyestalk on the expression of CLK itself or other proteins within the brain, potentially by CLK acting together with Cycle as transcriptional repressor, has yet to be investigated.

\subsubsection{Crustacean period-gene}

The period-gene of Drosophila is the first clock gene for which the structure was fully determined (331); it forms the core of oscillating gene products. Its product PER is another bHLH/PAS superfamily domain protein, acting as a transcriptional repressor in heterodimers together with TIM, which can bind to regulatory DNA sequences thereby effectively regulating their own expression in a negative feedback loop. This leads to oscillatory activation and repression of transcription of these clock genes. PER is indispensible for proper circadian rhythmicity, and Drosophila per-mutants are affected in several biological rhythms including locomotory activity (332) as well as pupal eclosion, larval heart beat rhythm and courtship song intervals (333, 334). The proper identification of PER-like molecules and analyses of their location and biological function in crustaceans would therefore be of great value.

In fact, the first and hitherto only evidence for the existence of a PER-like protein in a crustacean was provided successfully by immunohistochemistry only using an antibody against Drosophila PER in the crayfish $P$. clarkii. Immunoreactive PER was detected in distinct structures of the retina and optic ganglia, chiefly in photoreceptors and monopolar neurons of the lamina, as well as in lamina glia (23). However, the authors did not find circadian rhythmicity of per expression, and it thus remains to be demonstrated if PER is involved in the regulation of retinal oscillations of any nature. In particular, the expression of PER in several neuronal cell types could, unfortunately, not be linked directly to the autonomous ERG circadian rhythm.

\subsubsection{Crustacean cryptochrome-gene}

Cryptochrome (CRY) was identified first in Drosophila as a contributor to circadian control, which is expressed in $\mathrm{LN}_{\mathrm{v}}$ neurons (335). CRY is a flavin-adenin-dinucleotide/pterin-containing protein of ca. 60KDa capable of absorbing the light energy from blue light. Upon light stimulation, CRY undergoes conformational changes and autophosphorylation enabling direct interaction with the clock protein TIM, which results in the proteasome-mediated degradation of TIM (336). It, thus, interferes directly with the oscillation of the PER/TIM transcription factors but helps to adjust and actually reset the clock to environmental changes in light/dark-phases via light-driven interactions (337). CRY-mRNA as well as CRY-protein cycle in a circadian pattern, with highest CRY-mRNA levels at onset of light followed by a continuous decrease but rising again during the dark phase, whilst CRY protein was increasing prior to the CRY-mRNA increase in the dark phase (337). In insects other than Drosophila, paralogous cry-gene products exist (termed CRY-m mammalian like, or CRY2), which do not contribute to photic entrainment but act as transcriptional repressor of CLK/CYC-heterodimers, and, depending upon the species, even two CRY isoforms occur. The ancestral clock of insects was thus supposed to consist of two CRYs (CRY-d = Drosophila-like and CRY-m), together with even two similar TIM isoforms (TIM-m and TIM-d) and CYC as the main transcriptional factors (319).

Again in the crayfish P. clarkii, a CRY-like molecule has been detected for the first time by means of immunohistochemistry in neurons of the anterior median (AMC) and lateral olfactory cell clusters of the protocerebrum (clusters 
6 and 10; 338) and close to the proximal edge of the hemiellipsoid body complex in the medulla terminalis of the optic lobe. In addition, its presence as a single CRY-ir protein only and of a size similar to that of Drosophila CRY has been confirmed by Western blotting of tissue extracts (339). Whilst already assumed in the latter study, a clear-cut association of crayfish CRY with the extraretinal BPRs within the AMC cluster 6 has only recently been described for the crayfish $C$. destructor and P. clarkii (17) (cp. 3.4.). In the developing crayfish P. clarkii, eyestalk and brain tissue concentrations of CRY changed with regular daily rhythms (340). In the adult brain, CRY levels change with a circadian rhythm (but only in the AMC), which was considered suggestive of a possible function of CRY in crayfish circadian control. In eyestalk locations of the adult, apparently no significant circadian changes of CRY do occur (339). However, in the eyestalk of second post-embryonic stages (PO2) under LD conditions, CRY expression oscillates with a bimodal pattern but somewhat in antiphase to that in the brain (Eyestalk: high at 15:00ZT, low at 23:00 ZT; brain: low at 11:00ZT and high at 23:00ZT). In constant darkness, the rhythm runs freely only in the brain. In juveniles, CRY did not show any circadian rhythm in the eyestalk but an obvious rhythm in the brain (340). The discovery of crayfish CRY and its circadian changes during development (i) supports earlier findings on extraretinal effects of blue light on circadian ERG rhythms which are likely driven by CRY as the blue-light-sensitive photopigment and a possible component of the CPR and a putative brain oscillator $(235,298)$ and (ii) gives hints about a possible developmental plasticity in clock properties e.g. with regard to different period length in PO2 post-embryonic stages vs. juveniles (340). However, the most likely functional role of CRY in controlling circadian rhythmicity resides in its expression in the BPRs, which are the extraretinal photoreceptive elements mainly responsible for the light entrainment of rhythmic locomotion in adult crayfish but show some preference for green rather than blue light $(185,17)$.

\section{PERSPECTIVE}

The circadian rhythms of various biological phenomena are well described for several crustacean species, but investigations into the regulatory basis of these behaviours have usually not reached the cellular level of identified neuronal elements of the respective endogenous circadian clocks. Thus, most of our knowledge is merely phenomenological. However, only the deeper analysis of the mechanistic control of clocks lends promise towards a better understanding of the cellular basis of circadian rhythmicity. Crustaceans are a favourable group for neurobiological investigations in the field of comparative chronobiology: there is often a well-documented neurobiology of locomotory behaviours available and easy access to in vivo and in vitro electrophysiological analyses of identified neurons and nowadays also to their molecular biological manipulations, e.g. by promising RNAi approaches, as has already been shown in the cases of successful neuropeptide knock-downs in XOSG neurons $(341,342)$.

We finally present here several open questions that can be answered with the currently available information and methods at hand. Solutions to the problems behind these questions will likely provide fundamental insights into the physiology of crustacean circadian clocks:

- What is the primary molecular basis of the pacemaker oscillations? Several molecules are expressed with a circadian rhythm, but it remains to be shown which ones of these are necessary and sufficient for a self-sustaining rhythmicity. Especially comparisons of identified crustacean clock genes with those of insects may show the conservation of functionally important domains, thus, likely indicating the conservation of protein interactions responsible for similar regulatory principles. Investigations on the expression dynamics of clock genes in crustaceans would allow first insights into the functioning of crustacean clocks at the cellular level.

- How do the distinct pacemakers connect, synchronise, and entrain? Where are the synaptic connections? As discussed above, this is a very important yet unresolved topic at the systems level, but needs to be addressed at the cellular level, although significant interspecies differences may be revealed.

- Which is the most basic oscillation of the pacemaker(s)? Ultradian rhythms have been demonstrated in different systems, such as in the cases of the ERG sensory rhythms, the spontaneous CPR activity, and the fluctuations of serotonin and other mediators. It has been hypothesised that circadian rhythms are principally based upon ultradian rhythms, and that amplitudes and phases of their coupling interactions are important for an integrative functioning of distributed pacemakers (343).

- Which function(s) do clock genes similar to those of insects have in crustaceans? With available gene sequences, soon derived from many more genomes of a growing number of crustacean species (344), RNAi approaches, for instance, together with (established) behavioural analyses appear suitable for testing the functions of the clock genes. However, such gene ablation may still be inconclusive, as proteins can be pleiotropic in different clock systems of a given organism, but the analyses of circadian phenomena will show whether redundant control molecules exist that participate in different circadian systems of a given species.

- Which neuropeptides or small signalling molecules are used by the pacemaker(s)? Identities or similarities in primary structures of neuronal signalling molecules known to exist in both insects and crustaceans invite screening for distributions in crustacean CNSs with regard to the locations and possible functions of presumptive pacemaker structures. PDH-ir neurons and their co-transmitters may serve as a suitable starting point in this respect. However, such studies must be combined with analyses of circadian behaviours of the identified cells, suitable (cultured) tissues and intact specimens themselves, e.g. in terms of their locomotory, ERG, or other rhythms. Furthermore, upon 
identification of crustacean-specific neuropeptide isoforms and their precursors, injections of synthetic peptides and double-stranded RNAi preparations enable studies of manipulated circadian behaviours.

- Do circadian and circatidal clocks use identical or different molecular mechanisms? Is there mechanistic interaction or even integration between the two systems? Apart from behavioural data and entrainment experiments, the cellular localisation of distinct circatidal pacemakers has not been easily forthcoming and deserves further investigation. Clock genes that are similar in insects and crustaceans may also regulate circatidal clocks, but these have not yet been fully identified, located and/or functionally linked to well-known circatidal rhythms in crustaceans $(6,8)$. It is entirely possible that circadian and circatidal rhythms originate from different molecular components, and may have to be considered as convergent adaptations to different cues. Testing for the presence and functional significance of known (homologous) clock molecules in the two systems will, however, provide promising insights into their evolutionary origin, and, in particular, answer the question as to whether circadian clocks have indeed evolved from circatidal clocks (cp. 8).

- How were crustacean and insect pacemaker cells shaped during evolution, how did they gain functionality in rhythm control, and how does the distributed location of crustacean pacemakers relate to the evolution of clocks in the Pancrustacea? The Drosophila clock neuron clusters of a few morphologically and functionally distinct s-/l- $\mathrm{LN}_{\mathrm{v}} \mathrm{s}$ and $\mathrm{LN}_{\mathrm{d}} \mathrm{s}$ are likely a highly adapted clock system. However, PDH/PDF-ir neurons located next to the optic ganglia usually occur in most other insects $(57,316-318)$ and in diverse crustaceans $(138,140,141)$ in much larger numbers. They could, thus, represent a clock organisation less specialised than that in Drosophila. These considerations ultimately address questions about the ancestral organisation of arthropod clock neurons $(319,345)$, and how their functional and anatomical design evolved in the different taxa. Furthermore, comparisons with other arthropod taxa such as myriapods and chelicerates will be essential to understand which features most likely were already present in the arthropod ancestor and will help to clarify whether distributed clock systems are specific to crustaceans.

\section{ACKNOWLEDGEMENTS}

J.S. is a stipendiary of the Swedish Carl Tryggers Foundation which is thanked for its generous financial support. The same foundation and an additional research award from the Faculty of Natural Sciences at Stockholm University provided financial support for this study to H.D., and both organisations are, therefore, gratefully acknowledged. The authors wish to thank Prof. Dr. Steffen Harzsch, University of Greifswald, Germany, for generously providing original micrographs in figure 4, and an anonymous reviewer for very thoughtful comments and helpful corrections.

\section{REFERENCES}

1. V. Dvornyk, O. Vinogradova and E. Nevo: Origin and evolution of circadian clock genes in prokaryotes. Proc Natl Acad Sci USA 100, 2495-2500 (2003)

2. M. Rosbash: The implications of multiple circadian clock origins. PLoS Biol 7, e62 (2009)

3. E. Naylor: Rhythmic behaviour of decapod crustaceans. Symp Zool Soc Lond 59, 177-199 (1988)

4. E. Naylor: Marine animal behaviour in relation to lunar phase. Earth Moon Planets 85-86, 291-302 (2001)

5. G. Fleissner, K. Schuchardt, D. Neumann, G. Bali, G. Falkenberg and G. Fleissner: A lunar clock changes shielding pigment transparency in larval ocelli of Clunio marinus. Chronobiol Int 25, 17-30 (2008)

6. E. Naylor: Chronobiology of marine organisms. Cambridge Univ Press, Cambridge (2010)

7. E. Naylor: Crab clockworks: the case for interactive circatidal and circadian oscillators controlling rhythmic locomotor activity of Carcinus maenas. Chronobiol Int 13, 153-161 (1996)

8. D. Wilcockson and L. Zhang: Circatidal clocks. Curr Biol 18, R753-R755 (2008)

9. G. Y. Conan: Periodicity and phasing of molting. In: Factors in adult growth. (Eds.): A. M. Wenner. A. A. Balkema, Rotterdam, The Netherlands, 3, 73-99 (1985)

10. H. Aréchiga and L. Rodriguez-Sosa: Distributed circadian rhythmicity in the crustacean nervous system. In: The crustacean nervous system. (Eds.): K. Wiese. Springer, Berlin, 113-122 (2002)

11. M. L. Fanjul-Moles, E. Moreno-Sáenz, N. Villalobos-Hiriart and B. Fuentes-Pardo: ERG circadian rhythm in the course of ontogeny in crayfish. Comp Biochem Physiol 88A, 213-219 (1987) 
12. L. Rodriguez-Sosa, G. Calderón-Rosete and G. Flores: Circadian and ultradian rhythms in the crayfish caudal photoreceptor. Synpase 62, 643-652 (2008)

13. D. E. Bliss and J. R. Boyer: Environmental regulation of growth in the decapod crustacean Gecarcinus lateralis. Gen Com Endocrinol 4, 15-41 (1964)

14. D. E. Aiken: Photoperiod, endocrinology and the crustacean molt cycle. Science 164, 149-155 (1969)

15. E. Naylor, E. Zeng, P. Abello, C. G. Warman and D. G. Reid: Clock-controlled moulting rhythms in a marine crustacean: circatidal timing of metamorphic and copulatory moulting in the shore crab Carcinus maenas. Biol Rhythm Res 26, 426-427 (1995)

16. T. L. Page and J. L. Larimer: Entrainment of the circadian locomotor activity rhythm in crayfish. The role of the eyes and caudal photoreceptor. J comp Physiol 78, 107-120 (1972)

17. J. M. Sullivan, M. C. Genco, E. D. Marlow, J. L. Benton, B. S. Beltz and D. C. Sandeman: Brain photoreceptor pathways contributing to circadian rhythmicity in crayfish. Chronobiol Int 26, 1136-1168 (2009)

18. P. A. Collins: A coexistence mechanism for two freshwater prawns in the Parana river floodplain, Argentina. J Crustacean Biol 25, 219-225 (2005)

19. P. J. DeCoursey: Biological timing. In: Behavior and ecology. (Eds.): F. J. Vernberg and W. B. Vernberg. Academic Press, New York, 7, 107-162 (1983)

20. H. Aréchiga, J. L. Cortes, U. Garcia and L. Rodriguez-Sosa: Neuroendocrine correlates of circadian rhythmicity in Crustaceans. Am Zool 25, 265-274 (1985)

21. H. Aréchiga, F. Fernandez-Quiroz, F. Fernandez de Miguel and L. Rodriguez-Sosa: The circadian system of crustaceans. Chronobiol Int 10, 1-19 (1993)

22. M. L. Fanjul-Moles and J. Prieto-Sagredo: The circadian system of crayfish: a developmental approach. Microsc Res Tech 60, 291-301 (2003)

23. H. Aréchiga and L. Rodriguez-Sosa: Circadian clock function in isolated eyestalk tissue of crayfish. Proc R Soc Lond Ser B $265,1819-1823(1998)$

24. E. Naylor: Tidal and diurnal rhythms of locomotory activity in Carcinus maenas (L.). J Exp Biol 35, 602-610 (1958)

25. B. G. Williams and E. Naylor: Synchronisation of the locomotor tidal rhythm of Carcinus. J Exp Biol 51, 715-725 (1969)

26. M. L. Fanjul-Moles, M. Miranda-Anaya and J. Prieto: Circadian locomotor activity rhythm during ontogeny in crayfish Procambarus clarkii. Chronobiol Int 13, 15-26 (1996)

27. S. H. Jury, C. C. Chabot and W. H. Watson III: Daily and circadian rhythms of locomotor activity in the American lobster, Homarus americanus. J Exp Mar Biol Ecol 318, 61-70 (2005)

28. J. Aguzzi, J. B. Company and P. Abello: Locomotor activity rhythms of continental slope Nephrops norvegicus (Decapoda: Nephropidae). J Crust Biol 24, 282-290 (2004)

29. J. Aguzzi, D. Sarria, J. A. Garcia, J. Del Rio, F. Sarda and A. Manuel: A new tracking system for the measurement of diel locomotor rhythms in the Norway lobster, Nephrops norvegicus (L.). J Neurosci Meth 173, 215-224 (2008)

30. J. Aguzzi and F. Sarda: A history of recent advancements on Nephrops norvegicus behavioral and physiological rhythms. Rev Fish Biol Fisheries 18, 235-248 (2008)

31. G. P. Ennis: Endogenous rhythmicity associated with larval hatching in the lobster Homarus gammarus. J Mar Ass UK 53, 531-538 (1973)

32. G. P. Ennis: Observations on hatching and larval release in the lobster, Homarus americanus. J Fish Res Board Can 32, 2210-2213 (1975) 
33. J. R. Branford: The influence of daylength, temperature, and season on the hatching rhythm of Homarus gammarus. J Mar Ass UK 58, 639-658 (1978)

34. P. Abello, C. G. Warman and E. Naylor: Circatidal moulting rhythm in the shore crab Carcinus maenas. J Mar Assoc UK 77 , 277-280 (1997)

35. S. L. Waddy and D. E. Aiken: Timing of the metamorphic molt of the American lobster (Homarus americanus) is governed by a population-based, photoperiodically entrained daily rhythm. Can J Fish Aquat Sci 56, 2324-2330 (1999)

36. J. M. Bishop and W. F. Herrnkind: Burying and molting of pink shrimp, Penaeus duorarum (Crustacea: Penaeidae), under selected photoperiods of white light and UV-light. Biol Bull 150, 163-182 (1976)

37. P. Natarajan: Persistent locomotor rhythmicity in the prawns Penaeus indicus and P. monodon. Mar Biol 101, 339-346 (1989)

38. D. Bouchon: Biological clock in seasonal reproductive cycle in the ditch shrimp Palaemonetes varians Leach. I. Photoperiodic time measurement. J Exp Mar Biol Ecol 146, 1-12 (1991)

39. J. K. Douglass and J. H. Wilson: A tidal rhythm in phototaxis of larval grass shrimp (Palaemonetes pugio). Mar Freshw Behav Physiol 19, 159-173 (1992)

40. J. Aguzzi, J. B. Company and J. A. Garcia: The circadian behavioural regulation of the shrimp, Processa canaliculata Leach, 1815 (Decapoda, Processidae) in relation to depth, ontogeny, and the reproductive cycle. Crustaceana 81, 1301-1316 (2008)

41. M. Fingerman: Comparative physiology: chromatophores. Ann Rev Physiol 32, 345-372 (1970)

42. M. Fingerman: The physiology and pharmacology of crustacean chromatophores. Amer Zool 25, 233-252 (1985)

43. C. Zeng and E. Naylor: Synchronization of endogenous tidal vertical migration rhythms in laboratory-hatched larvae of the crab Carcinus maenas. J Exp Mar Biol Ecol 198, 269-289 (1996)

44. K. Thorisson: How are the vertical migrations of copepods controlled? J Exp Mar Biol Ecol 329, 86-100 (2006)

45. K. M. Svadling: Krill migration: up and down all night. Curr Biol 16, R173-R175 (2006)

46. E. J. Murphy, J. L. Watkins, P. N. Trathan, K. Reid, M. P. Meredith, S. E. Thorpe, N. M. Johnston, A. Clarke, G. A. Tarling, M. A. Collins, J. Forcada, R. S. Shreeve, A. Atkinson, R. Korb, M. J. Whitehouse, P. Ward, P. G. Rodhouse, P. Enderlein, A. G. Hirst, A. R. Martin, S. L. Hill, I. J. Staniland, D. W. Pond, D. R. Briggs, N. J. Cunningham and A. H. Fleming: Spatial and temporal operation of the Scotia Sea ecosystem: a review of large-scale links in a krill centred food web. Philos Trans $R$ Soc Lond B Biol Sci. 362, 113-148. (2007)

47. E. Gaten, G. Tarling, H. Dowse, C. Kyriacou and E. Rosato: Is vertical migration in Antarctic krill (Euphausia superba) influenced by an underlying circadian rhythm? J Genet 87, 473-483 (2008)

48. J. Ringelberg: The photobehaviour of Daphnia spp. as a model to explain diel vertical migration. Biol Rev 74, 397-423 (1999)

49. D. Benzid, L. De Jong, C. Lejeus, P. Chevaldonné and X. Moreau: Serotonin expression in the optic lobes of cavernicolous crustaceans during the light-dark transition phase: Role of the lamina ganglionaris. J Exp Mar Biol Ecol 335, 74-81 (2006)

50. M. L. Reaka: Lunar and tidal periodicity of molting and reproduction in stomadopod Crustacea: a selfish herd hypothesis. Biol Bull 150, 468-490 (1976)

51. R. B. Forward jr: Larval release rhythms of decapod crustaceans: an overview. Bull Marine Sci 41, 165-176 (1987)

52. M. J. Vansteensel, S. Michel and J. H. Meijer: Organization of cell and tissue circadian pacemakers: a comparison among species. Brain Res Rev 58, 18-47 (2008)

53. C. Helfrich-Förster: The circadian clock in the brain: a structural and functional comparison between mammals and insects. $J$ Comp Physiol A 190, 601-613 (2004)

54. T. L. Page: Neural and endocrine control of circadian rhythmicity in invertebrates. In: Handbook of Behavioral Neurobiology, Vol. 4: Biological Rhythms. (Eds.): J. Aschoff. Plenum Press, New York, 145-172 (1981) 
55. J. C. Dunlap: Molecular bases for circadian clocks. Cell 96, 271-290 (1999)

56. F. W. Turek, C. Dugovic and P. C. Zee: Current understanding of the circadian clock and the clinical implications for neurological disorders. Arch Neurol 58, 1781-18787 (2001)

57. C. Helfrich-Förster, M. Stengl and U. Homberg: Organization of the circadian system in insects. Chronobiol Int 15, 567-594 (1998)

58. C. Helfrich-Förster: The neuroarchitecture of the circadian clock in the brain of Drosophila melanogaster. Microsc Res Tech 62, 94-102 (2003)

59. M. N. Nitabach and P. H. Taghert: Organization of the Drosophila circadian control circuit. Curr Biol 18, R84-R93 (2008)

60. B. Grima, E. Chelot, R. Xia and F. Rouyer: Morning and evening peaks of activity rely on different clock neurons of the Drosophila brain. Nature 431, 869-873 (2004)

61. D. Stoleru, Y. Peng, J. Agosto and M. Rosbash: Coupled oscillators control morning and evening locomotor behaviour of Drosophila. Nature 431, 862-868 (2004)

62. C. Helfrich-Förster, O. T. Shafer, C. Wülbeck, E. Grieshaber, D. Rieger and P. H. Taghert: Development and morphology of the clock-gene-expressing lateral neurons of Drosophila melanogaster. J Comp Neurol 500, 47-70 (2007)

63. M. R. Ralph, R. G. Foster, F. C. Davis and M. Menaker: Transplanted suprachiasmatic nucleus determines circadian period. Science 247, 975-978 (1990)

64. D. K. Welsh, D. E. Logothetis, M. Meister and S. M. Reppert: Individual neurons dissociated from rat suprachiasmatic nucleus express independently phased circadian firing rhythms. Neuron 14, $697-706$ (1995)

65. K. E. van Esseveldt, M. N. Lehman and G. J. Boer: The suprachiasmatic nucleus and the circadian time-keeping system revisited. Brain Res Rev 33, 34-77 (2000)

66. S. M. Reppert and D. R. Weaver: Coordination of circadian timing in mammals. Nature 418, 935-941 (2002)

67. R. Allada, P. Emery, J. S. Takahashi and M. Rosbash: Stopping time: the genetics of fly and mouse circadian clocks. Annu Rev Neurosci 24, 1091-1119 (2001)

68. S. L. Harmer, S. Panda and S. A. Kay: Molecular bases of circadian rhythms. Annu Rev Cell Dev Biol 17, 215-253 (2001)

69. R. G. Foster and C. Helfrich-Förster: The regulation of circadian clocks by light in fruit flies and mice. Phil Trans R Soc Lond B 356, 1779-1789 (2001)

70. S. Panda, J. B. Hogenesch and S. A. Kay: Circadian rhythms from flies to human. Nature 417, 329-335 (2002)

71. C. Helfrich-Förster: Robust circadian rhythmicity of Drosophila melanogaster requires the presence of lateral neurons: a brain-behavioral study of disconnected mutants. J Comp Physiol A 182, 435-453 (1998)

72. P. H. Taghert and O. T. Shafer: Mechanisms of clock output in the Drosophila circadian pacemaker system. J Biol Rhythms 21, 445-457 (2006)

73. H. Aréchiga and A. Huberman: Hormonal modulation of circadian rhythmicity in crustaceans. In: Comparative aspects of neuroendocrine control of behavior. (Eds.): C. Valverde and H. Aréchiga. Karger, Basel, 6, 16-34 (1980)

74. E. Naylor and B. G. Williams: Effects of eyestalk removal on rhythmic locomotor activity in Carcinus. J Exp Biol 49, 107$116(1968)$

75. B. Barrera-Mera: Effect of cerebroid ganglion lesion on ERG circadian rhythm in the crayfish. Physiol Behav 17, 59-64 (1976)

76. E. Frixione, H. Aréchiga and V. Tsutsumi: Photomechanical migrations of pigment granules along the retinula cells of the crayfish. J Neurobiol 10, 573-590 (1979) 
77. J. L. Kallen, N. R. Rigiani and H. J. A. J. Trompenaars: Aspects of entrainment of CHH cell activity and hemolymph glucose levels in the crayfish. Biol Bull 175, 137-143 (1988)

78. B. Barrera-Mera and G. D. Block: Protocerebral circadian pacemakers in crayfish: evidence for mutually coupled pacemakers. Brain Res 522, 241-245 (1990)

79. P. S. Reddy: Suppression of the diurnal rhythm of oxygen uptake by eyestalk ablation in the crab Oziotelphusa senex senex Fabricius. Arch Int Phsiol Biochim Biophys 99, 393-395 (1991)

80. M. Miranda-Anaya, B. Barrera-Mera and E. Ramirez-Lomeli: Circadian locomotor activity rhythm in the freshwater crab Pseudothelphusa americana (De Saussure, 1857): effect of eyestalk ablation. Biol Rhythm Res 34, 167-176 (2003)

81. H. Kalmus: Über einen latenten physiologischen Farbwechsel beim Flusskrebs Potamobius astacus und seine hormonelle Beinflussung. Z Vergl Physiol 25, 784-797 (1938)

82. T. L. Page and J. L. Larimer: Neural control of circadian rhythmicicty in the crayfish. II. The ERG amplitude rhythm. $J$ comp Physiol 97, 81-96 (1975)

83. J. L. Larimer and J. T. F. Smith: Circadian rhythm of retinal sensitivity in the crayfish: modulation by the cerebral and optic ganglia. J Comp Physiol 136, 313-326 (1980)

84. B. Fuentes-Pardo and V. Inclan-Rubio: Correlation between the motor and electroretinographic circadian rhythms in crayfish Procambarus bouvieri (Ortmann). Comp Biochem Physiol A 68, 477-485 (1981)

85. H. Aréchiga, A. Huberman and E. Naylor: Hormonal modulation of circadian neural activity in Carcinus maenas (L.). Proc $R$ Soc Lond Ser B 187, 299-313 (1974)

86. W. H. Gordon, J. L. Larimer and T. L. Page: Circumesophageal interneurons required for reflexive and circadian locomotor behaviors in crayfish. J comp Physiol 116, 227-238 (1977)

87. V. Inclan-Rubio and B. Fuentes-Pardo: Caudal photoreceptors synchronize the circadian rhythms in crayfish. II: Functional relationships between caudal and visual photoreceptors. Comp Biochem Physiol A 86, 529-536 (1987)

88. O. H. Hérnandez and B. Fuentes-Pardo: Cerebroid ganglion is the presumptive pacemaker of the circadian rhythm of electrical response to light in the crayfish. Biol Rhythm Res 32, 125-144 (2001)

89. C. G. Warman and E. Naylor: Evidence for multiple, cue-specific circatidal clocks in the shore crab Carcinus maenas. J Exp Mar Biol Ecol 189, 93-101 (1995)

90. J. Zrzavý, V. Hypsa and M. Vlaskova: Arthropod phylogeny: taxonomic congruence, total evi-dence and conditional combination approaches to morphological and molecular data sets. In: Arthropod Relationships. (Eds.): R. A. Fortey and R. H. Thomas. Chapman and Hall, London, 97-107 (1998)

91. W. Dohle: Are the insects terrestrial crustaceans? A discussion of some new facts and arguments and the proposal of the proper name "Tetraconata" for the monophyletic unit Crustacea + Hexapoda. Ann Soc Entomol France NS 37, 85-103 (2001)

92. G. Giribet, G. D. Edgecombe and W. C. Wheeler: Arthropod phylogeny based on eight molecular loci and morphology. Nature 413, 157-161 (2001)

93. S. Richter: The Tetraconata concept: hexapod-crustacean relationships and the phylogeny of Crustacea. Org Div Evol 2, 217237 (2002)

94. E. Hallberg and R. Elofsson: Construction of the pigment shield of the crustacean compound eye: a review. J Crust Biol 9 , 359-372 (1991)

95. K. R. Rao: Crustacean pigmentary effect hormones: chemistry and functions of RPCH, PDH, and related peptides. Amer Zool 41, 364-379 (2001)

96. R. Bennitt: Diurnal rhythm in the proximal cells of the crayfish retina. Physiol Zool 5, 65-69 (1932)

97. J. H. Welsh: Diurnal rhythm of the distal pigment cells in the eyes of certain crustaceans. Proc Natl Acad Sci USA 16, 386395 (1930) 
98. J. H. Welsh: Further evidence of a diurnal rhythm in the movement of pigment cells in eyes of crustaceans. Biol Bull 68, 247$252(1935)$

99. L. M. W. Leggett and D. G. Stavenga: Diurnal changes in angular sensitivity of crab photoreceptors. J comp Physiol 144, 99$109(1981)$

100. S. Cellier-Michel and J. L. Berthon: Rhythmicity of the pigments in the compound eye of Daphnia longispina (Cladocera). $J$ Freshw Ecol 18, 445-450 (2003)

101. C. Ludolph, D. Pagnanelli and M. Mote: Neural control of migration of proximal pigment by retinular cells of the swimming crab Callinectes sapidus. Biol Bull 145, 150-170 (1973)

102. E. Frixione and J. Hernández: Modulation of screening-pigment position in crayfish photoreceptors by serotonin: possible involvement of Na+/K+-ATPase activity. J Exp Biol 143, 459-473 (1989)

103. E. G. Escamilla-Chimal, F. van Herp and M. L. Fanjul-Moles: Daily variations in crustacean hyperglycaemic hormone and serotonin immunoreactivity during the development of crayfish. J Exp Biol 204, 1073-1081 (2001)

104. W. C. Mobberly jr.: The effect of constant conditions of light and darkness on the diurnal rhythm of the distal retinal pigment of the crayfish Faxonella clypeata. Ohio J Sci 64, 185-194 (1964)

105. K. R. Rao: Pigmentary effectors. In: The biology of Crustacea. (Eds.): D. E. Bliss and L. H. Mantel. Acad Press, Orlando, FL, 9, 395-463 (1985)

106. K. P. Bryceson: The effect of screening pigment migration on spectral sensitivity in a crayfish reflecting superposition eye. $J$ Exp Biol 125, 401-404 (1986)

107. K. P. Bryceson: Diurnal changes in photoreceptor sensitivity in a reflecting superposition eye. J Comp Physiol A 158, 573582 (1986)

108. M. L. Fanjul-Moles and B. Fuentes-Pardo: Spectral sensitivity in the course of ontogeny of the crayfish Procambarus clarkii. Comp Biochem Physiol 91A, 61-66 (1988)

109. T. Hariyama, V. B. Meyer-Rochow and E. Eguchi: Diurnal changes in structure and function of the compound eye of Ligia exotica (Crustacea, Isopoda). J Exp Biol 123, 1-26 (1986)

110. T. Hariyama, V. Meyer-Rochow, T. Kawauchi, Y. Takaku and Y. Tsukahara: Diurnal changes in retinula cell sensitivities and receptive fields (two-dimensional angular sensitivity functions) in the apposition eyes of Ligia exotica (Crustacea, Isopoda). J Exp Biol 204, 239-248 (2001)

111. L. H. Kleinholz: Eye-stalk hormone and the movement of distal retinal pigment in Palaemonetes. Proc Natl Acad Sci USA 20, 659 (1934)

112. L. H. Kleinholz: Crustacean eye-stalk hormone and retinal pigment migration. Biol Bull 70, 159 (1936)

113. J. H. Welsh: The action of eye-stalk extracts on retinal pigment migration in the crayfish, Cambarus bartoni. Biol Bull 77 , 119-125 (1939)

114. J. H. Welsh: The sinus gland and 24-hours cycle of retinal pigment migration in the crayfish. J exp Zool 86, 35-49 (1941)

115. R. Smith: The role of the sinus gland in retinal pigment migration in grapsoid crabs. Biol Bull 95, 169-185 (1948)

116. J. Hernández-Falcón, E. Moreno-Sáenz, J. M. Farias and B. Fuentes-Pardo: Role of the sinus gland in crayfish circadian rhythmicity. I. Pseudopupil circadian rhythm. Comp Biochem Physiol A 87, 111-118 (1987)

117. L. H. Kleinholz: Hormonal regulation of retinal pigment migration in crustaceans. In: The functional organization of the compound eye. (Eds.): C. G. Bernhard. Pergamon Press, Oxford, 89- 101 (1966)

118. K. Naka and M. Kuwabara: Two components from the compund eye of the crayfish. J Exp Biol 36, 51-61 (1959) 
119. J. Sanchez and B. Fuentes-Pardo: Circadian rhythm in the amplitude of the electroretinogram in the isolated eyestalk of the crayfish. Comp Biochem Physiol 56A, 601-609 (1977)

120. H. Aréchiga and C. A. G. Wiersma: Circadian rhythm of responsiveness in crayfish visual circuits. J Neurobiol $1,71-85$ (1969)

121. B. Barrera-Mera: Neural coupling between left and right electroretinographic circadian oscillations in the crayfish $P$. bouvieri. Comp Biochem Physiol A 61, 427-432 (1978)

122. E. Moreno-Sáenz, B. Fuentes-Pardo and J. Hernández-Falcón: Photoentrainment of the circadian rhythm in the electroretinogram of the crayfish and its dependence on the sinus gland. J exp Zool 264, 144-152 (1992)

123. D. N. Blaustein, C. D. Derby, R. B. Simmons and A. C. Beall: Structure of the brain and medulla terminalis of the spiny lobster Panulirus argus and the crayfish Procambarus clarkii, with an emphasis on olfactory centers. J Crust Biol 8, 43-51 (1988)

124. S. Harzsch: The phylogenetic significance of crustacean optic neuropils and chiasmata: a re-examination. J Comp Neurol 453, 10-21 (2002)

125. N. J. Strausfeld: The evolution of crustacean and insect optic lobes and the origins of chiasmata. Arthropod Struct Dev 34 , $235-256(2005)$

126. H. Aréchiga, U. Garcia and L. Rodriguez-Sosa: Neurosecretory role of the crustacean eyestalk in the control of neural activity. In: Model neural networks and behaviour. (Eds.): A. I. Selverston. Plenum Press, New York, 361-379 (1985)

127. S. Mangerich, R. Keller and H. Dircksen: Immunocytochemical identification of structures containing putative red pigmentconcentrating hormone in two species of decapod crustaceans. Cell Tissue Res 245, 377-386 (1986)

128. H. Dircksen, S. G. Webster and R. Keller: Immunocytochemical demonstration of the neurosecretory systems containing putative moult-inhibiting and hyperglycemic hormone in the eyestalk of brachyuran crustaceans. Cell Tissue Res 251, 3-12 (1988)

129. J. Kallen and J. J. Meusy: Do the neurohormones VIH (vitellogenesis inhibiting hormone and CHH (crustacean hyperglycemic hormone) of crustaceans have a common precursor? Immunolocalization of VIH and CHH in the X-organ sinus gland complex of lobster Homarus americanus. Invert Reprod Dev 16, 43-52 (1989)

130. H. G. Marco and G. Gäde: A comparative immunocytochemical study of the hyperglycaemic, moult-inhibiting and vitellogenesis-inhibiting neurohormone family in three species of decapod Crustacea. Cell Tissue Res 295, 171-182 (1999)

131. D. Böcking, H. Dircksen and R. Keller: The crustacean neuropeptides of the CHH/MIH/GIH family: Structures and biological activities. In: The Crustacean Nervous System. (Eds.): K. Wiese. Springer, Berlin, Heidelberg, 84-97 (2002)

132. Y. W. Hsu, D. I. Messinger, J. S. Chung, S. G. Webster, H. O. de la Iglesia and A. E. Christie: Members of the crustacean hyperglycemic hormone $(\mathrm{CHH})$ peptide family are differentially distributed both between and within the neuroendocrine organs of Cancer crabs: implications for differential release and pleiotropic function. J Exp Biol. 209, 3241-3256 (2006)

133. C. Ollivaux, J. Vinh, D. Soyez and J. Y. Toullec: Crustacean hyperglycemic and vitellogenesis-inhibiting hormones in the lobster Homarus gammarus - Implications for structural and functional evolution of a neuropeptide family. FEBS J 273, 2151$2160(2006)$

134. G. Smith and E. Naylor: The neurosecretory system of the eyestalk of Carcinus maenas (Crustacea: Decapoda). J Zool Lond $166,313-321$ (1972)

135. R. D. Andrew, I. Orchard and A. S. M. Saleuddin: Structural re-evaluation of the neurosecretory system in the crayfish eyestalk. Cell Tissue Res 190, 235-246 (1978)

136. P. P. Jaros: Tracing of neurosecretory neurons in crayfish optic ganglia by cobalt iontophoresis. Cell Tissue Res 194, 297$302(1978)$

137. H. Dircksen, C. A. Zahnow, G. Gaus, R. Keller, K. Ranga Rao and J. P. Riehm: The ultrastructure of nerve endings containing pigment-dispersing hormone $(\mathrm{PDH})$ in crustacean sinus glands: Identification by an antiserum against a synthetic PDH. Cell Tissue Res 250, 377-387 (1987) 
138. S. Mangerich, R. Keller, H. Dircksen, K. R. Rao and J. P. Riehm: Immunocytochemical localization of pigment-dispersing hormone (PDH) and its coexistence with FMRFamide-immunoreactive material in the eyestalks of the decapod crustaceans Carcinus maenas and Orconectes limosus. Cell Tissue Res 250, 365-375 (1987)

139. S. Mangerich and R. Keller: Localization of pigment-dispersing hormone (PDH) immunoreactivity in the central nervous system of Carcinus maenas and Orconectes limosus (Crustacea), with reference to FMRFamide immunoreactivity in O. limosus. Cell Tissue Res 253, 199-208 (1988)

140. Y. W. A. Hsu, E. A. Stemmler, D. I. Messinger, P. S. Dickinson, A. E. Christie and H. O. de la Iglesia: Cloning and differential expression of two beta-pigment-dispersing hormone (beta-PDH) isoforms in the crab Cancer productus: Evidence for authentic beta-PDH as a local neurotransmitter and beta-PDH II as a humoral factor. J Comp Neurol 508, 197-211 (2008)

141. S. Harzsch, H. Dircksen and B. Beltz: Development of pigment-dispersing hormone-immunoreactive neurons in the American lobster: homology to the insect circadian pacemaker system? Cell Tissue Res 335, 417-429 (2009)

142. R. M. Glantz, M. D. Kirk and H. Aréchiga: Light input to crustacean neurosecretory cells. Brain Res 265, 307-311 (1983)

143. P. Fernlund and L. Josefsson: Crustacean colour change hormone. Amino acid sequence and chemical synthesis. Science $177,173-175(1972)$

144. G. Gäde: Peptides of the adipokinetic hormone/red pigment-concentrating hormone family: a new take on biodiversity. Ann N Y Acad Sci 1163, 125-136 (2009)

145. G. Gaus, L. H. Kleinholz, G. Kegel and R. Keller: Isolation and characterization of of red-pigment-concentrating hormone from six crustacean species. J Comp Physiol B 160, 373-379 (1990)

146. G. Gaus and H. Stieve: The effect of neuropeptides on the ERG of the crayfish Orconectes limosus. Z Naturforsch C 47 , 300-303 (1992)

147. A. Garfias, L. Rodriguez-Sosa and H. Aréchiga: Modulation of crayfish retinal function by red pigment concentrating hormone. J Exp Biol 198, 1447-1454 (1995)

148. P. S. Dickinson, C. Mecsas and E. Marder: Neuropeptide fusion of two motor-pattern generator circuits. Nature 344, 155$158(1990)$

149. P. S. Dickinson, C. Mecsas, J. Hetling and K. Terio: The neuropeptide red pigment concentrating hormone affects rhythmic pattern generation at multiple sites. J Neurophysiol 69, 1475-1483 (1993)

150. C. M. Sherff and B. Mulloney: Red pigment concentrating hormone is a modulator of the crayfish swimmeret system. $J$ Exp Biol 155, 21-35 (1991)

151. L. Rodriguez-Sosa, J. Calderon, E. Becerra and H. Aréchiga: Regional distribution and immunocytological localization of red pigment concentrating hormone in the crayfish eyestalk. Gen Comp Endocrinol 95, 443-456 (1994)

152. T. Nussbaum and H. Dircksen: Neuronal pathways of classical crustacean neurohormones in the central nervous system of the woodlouse, Oniscus asellus (L.). Phil Trans R Soc Lond B 347, 139-154 (1995)

153. M. Preciado, V. Tsutsumi and H. Aréchiga: Ultrastructural features of neurosecretory cells in the medulla externa of the crayfish eyestalk. Gen Comp Endocrinol 95, 432-442 (1994)

154. M. D. Kirk, J. I. Prugh and R. M. Glantz: Retinal illumination produces synaptic inhibition of a neurosecretory organ in the crayfish Pacifastacus leniusculus (Dana). J Neurobiol 14, 473-480 (1983)

155. S. W. Fingerman and M. Fingerman: Circadian variation in the levels of red pigment-dispersing hormone and 5hydroxytryptamine in the eyestalks of the fiddler crab, Uca pugilator. Comp Biochem Physiol C 56, 5-8 (1977)

156. L. Rodriguez-Sosa, M. T. de la Vega and H. Aréchiga: Circadian rhythm of content of red pigment concentrating hormone in the crayfish eyestalk. Comp Biochem Physiol C 109, 101-108 (1994)

157. F. Martinez-Perez, S. Zinker, G. Aguilar, J. Valdes and H. Aréchiga: Circadian oscillations of RPCH gene expression in the eyestalk of the crayfish Cherax quadricarinatus. Peptides 26, 2434-2444 (2005) 
158. S.-M. Chan, P.-L. Gu, K.-H. Chu and S. S. Tobe: Crustacean neuropeptide genes of the CHH/MIH/GIH family: implications from molecular studies. Gen Comp Endocrinol 134, 214-219 (2003)

159. S. H. Chen, C. Y. Lin and C. M. Kuo: In silico analysis of crustacean hyperglycemic hormone family. Mar Biotechnol (NY) 7, 193-206 (2005)

160. F. van Herp: Molecular, cytological and physiological aspects of the crustacean hyperglycemic hormone family. In: Recent advances in arthropod endocrinology. (Eds.): G. M. Coast and S. G. Webster. Cambridge Univ. Press, Cambridge, 53-70 (1998)

161. R. Keller, G. Kegel, B. Reichwein, D. Sedlmeier and D. Soyez: Biological effects of neurohormones of the CHH/MIH/GIH peptide family in crustaceans. In: Recent developments in comparative endocrinology and neurobiology. (Eds.): E. W. Roubos, S. E. Wendelaar Bonga, H. Vaudry and A. De Loof. Shaker, Publishing B.V., Maastricht, 209-212 (1999)

162. M. L. Fanjul-Moles: Biochemical and functional aspects of crustacean hyperglycemic hormone in decapod crustaceans: Review and update. Comp Biochem Physiol C 142, 390-400 (2006)

163. J. L. Gorgels-Kallen and C. E. M. Voorter: The secretory dynamics of the CHH-producing cell group in the eyestalk of the crayfish, Astacus leptodactylus, in the course of the day/night cycle. Cell Tissue Res 241, 361-366 (1985)

164. R. S. Leuven, P. P. Jaros, F. Van Herp and R. Keller: Species or group specificity in biological and immunological studies of crustacean hyperglycemic hormone. Gen Comp Endocrinol 46, 288-296 (1982)

165. H. Dircksen, D. Böcking, U. Heyn, C. Mandel, J. S. Chung, G. Baggerman, P. Verhaert, S. Daufeldt, T. Plösch, P. P. Jaros, E. Waelkens, R. Keller and S. G. Webster: Crustacean hyperglycaemic hormone (CHH)-like peptides and CHH-precursor-related peptides from pericardial organ neurosecretory cells in the shore crab, Carcinus maenas, are putatively spliced and modified products of multiple genes. Biochem J 356, 159-170 (2001)

166. S. H. Chen, C. Y. Lin and C. M. Kuo: Cloning of two crustacean hyperglycemic hormone isoforms in freshwater giant prawn (Macrobrachium rosenbergii): evidence of alternative splicing. Mar Biotechnol (NY) 6, 83-94 (2004)

167. J. Y. Toullec, L. Serrano, P. Lopez, D. Soyez and C. Spanings-Pierrot: The crustacean hyperglycemic hormones from an euryhaline crab Pachygrapsus marmoratus and a fresh water crab Potamon ibericum: eyestalk and pericardial isoforms. Peptides $27,1269-1280(2006)$

168. J. S. Chung and N. Zmora: Functional studies of crustacean hyperglycemic hormones (CHHs) of the blue crab, Callinectes sapidus - the expression and release of CHH in eyestalk and pericardial organ in response to environmental stress. FEBS $J 275$, 693-704 (2008)

169. E. S. Chang, S. A. Chang, B. S. Beltz and E. A. Kravitz: Crustacean hyperglycemic hormone in the lobster nervous system: localization and release from cells in the subesophageal ganglion and thoracic second roots. J Comp Neurol 414, 50-56 (1999)

170. H. Dircksen, A. Basu, E. Chang, B. Beltz and E. Kravitz: Crustacean hyperglycemic hormone (CHH) in the lobster nervous system: localization to peripheral neurosecretory cells along thoracic second roots. Soc Neurosci Abstr 26, 1168 (2000)

171. H. Dircksen, F. Elghazali, E. Kravitz and D. Soyez: Neurons producing related crustacean hyperglycemic hormones (CHH)and ion transport peptides (ITP) in arthropods. Uppsala J Med Sci Suppl 55, 32 (2004)

172. A. Hamann: Die neuroendokrine Steuerung tagesrhythmischer Blutzuckerschwankungen durch die Sinusdrüse beim Flusskrebs. J comp Physiol 89, 197-214 (1974)

173. K. Parvathy Rajan, H. H. Kharouf and A. P. M. Lockwood: Rhythmic cycles of blood sugar concentrations in the crab Carcinus maenas. In: Cyclic phenomena in marine plants and animals. (Eds.): E. Naylor and R. G. Hartnoll. Pergamon Press, Oxford, 451-458 (1979)

174. J. L. Kallen, S. L. Abrahamse and F. van Herp: Circadian rhythmicity of the crustacean hyperglycemic hormone (CHH) in the hemolymph of the crayfish. Biol Bull 179, 351-357 (1990)

175. A. Tilden, J. Alt, K. Brummer, R. Groth, K. Herwig, A. Wilson and S. Wilson: Modulatory effects of melatonin on behavior, hemolymph metabolites, and neurotransmitter release in crayfish. Brain Res 992, 252-262 (2003) 
176. M. L. Fanjul-Moles, E. G. Escamilla-Chimal, R. Salceda, P. G. Giulianini and G. Sanchez-Chavez: Circadian modulation of crustacean hyperglycemic hormone in crayfish eyestalk and retina. Chronobiol Int 27, 34-51. (2010)

177. J. Aguzzi, J. B. Company, F. Sarda, J. Sanchez-Pardo, J. A. Garcia and G. Rotllant: Is the glucose concentration in the haemolymph a suitable indicator of circadian rhythmicity in Nephrops norvegicus (Decapoda, Nephropidae)? Crustaceana 77 , $213-229$ (2004)

178. J. A. Garcia and H. Aréchiga: Regulation of crustacean neurosecretory cell activity. Cell Mol Neurobiol 18, 81-99 (1998)

179. I. I. Uribe, L. Rodriguez-Sosa and H. Aréchiga: Diurnal patterns of electrical activity in crayfish neurosecretory cells. Biol Rhythm Res 29, 453-463 (1998)

180. R. Keller and J. Beyer: Zur hyperglykämischen Wirkung von Serotonin und Augenstielextrakt beim Flusskrebs Orconectes limosus. Z vergl Physiol 59, 78-85 (1968)

181. E. G. Escamilla-Chimal, M. Hiriart, M. C. Sanchez-Soto and M. L. Fanjul-Moles: Serotonin modulation of CHH secretion by isolated cells of the crayfish retina and optic lobe. Gen Comp Endocrinol 125, 283-290 (2002)

182. U. Garcia, C. Onetti, R. Valdiosera and H. Aréchiga: Excitatory action of gamma-aminobutyric acid (GABA) on crustacean neurosecretory cells. Cell Mol Neurobiol 14, 71-88 (1994)

183. R. Alvarado Álvarez, M. G. P. Villalobos, G. Calderón Rosete, L. Rodríguez Sosa and H. Aréchiga: Dopaminergic modulation of neurosecretory cells in the crayfish. Cell Mol Neurobiol 25, 345-370 (2005)

184. D. C. Sandeman, R. E. Sandeman and A. R. Aitken: Atlas of serotonin containing neurons in the optic lobes and brain of the crayfish Cherax destructor. J Comp Neurol 269, 465-478 (1988)

185. D. C. Sandeman, R. E. Sandeman and H. G. de Couet: Extraretinal photoreceptors in the brain of the crayfish Cherax destructor. J Neurobiol 21, 619-629 (1990)

186. F. van Herp and J. L. Kallen: Neuropeptides and neurotransmitters in the X-organ sinus gland complex, an important neuroendocrine integration centre in the eyestalk of Crustacea. In: Comparative aspects of neuropeptide function. (Eds.): E. Florey and G. B. Stefano. Manchester Univ. Press, Manchester, 211-221 (1991)

187. H. Aréchiga, B. Chavez and R. M. Glantz: Dye coupling and gap junctions between crustacean neurosecretory cells. Brain Res 326, 183-187 (1985)

188. R. Alvarado-Álvarez, U. G. Hernandez and H. Arechiga: Electrotonic coupling between neurosecretory-cells in the crayfish eyestalk. Brain Res 613, 43-48 (1993)

189. J. L. Gorgels-Kallen and J. T. A. Mey: Immunocytochemical study of the hyperglycemic hormone (CHH)-producing system in the eyestalk of the crayfish Astacus leptodactylus, during larval and postlarval development. J Morphol 183, 155-163 (1985)

190. J. S. Chung and S. G. Webster: Expression and release patterns of neuropeptides during embryonic development and hatching of the green shore crab, Carcinus maenas. Development 131, 4751-4761 (2004)

191. A. Yasuda, Y. Yasuda, T. Fujita and Y. Naya: Characterization of crustacean hyperglycemic hormone from the crayfish (Procambarus clarkii): multiplicity of molecular forms by stereoinversion and diverse functions. Gen Comp Endocrinol 95, 387398 (1994)

192. T. H. Moller and J. R. Branford: A circadian hatching rhythm in Nephrops norvegicus (Crustacea: Decapoda). In: Cyclic phenomena in marine plants and animals. (Eds.): E. Naylor and R. G. Hartnoll. Pergamon Press, Oxford, $391-397$ (1979)

193. M. Saigusa: Hatching controlled by the circatidal clock, and the role of the medulla terminalis in the optic peduncle of the eyestalk, in an estuarine crab Sesarma haematocheir. J Exp Biol 205, 3487-3504 (2002)

194. T. A. Ziegler and R. B. Forward Jr: Larval release rhythm of the mole crab Emerita talpoida (Say). Biol Bull 209, 194-203 (2005)

195. R. B. Forward Jr: Larval biology of the crab Rhithropanopeus harrisii (Gould): a synthesis. Biol Bull 216, 243-256 (2009) 
196. L. H. Kleinholz, H. Esper, C. Jonson and F. Kimball: Neurosecretion and crustacean retinal pigment hormone: assay and properties of light adapting hormone. Biol Bull 123, 317-319 (1962)

197. L. H. Kleinholz, D. B. Carlisle, O. Pflueger and P. R. Burgess: Neurosecretion and crustacean retinal pigment hormone: distribution of light-adapting hormone. Biol Bull 122, 73-85 (1962)

198. F. C. Granato, T. S. Tironi, F. E. Maciel, C. E. Rosa, M. A. Vargas and L. E. Maia Nery: Circadian rhythm of pigment migration induced by chromatrophorotropins in melanophores of the crab Chasmagnathus granulata. Comp Biochem Physiol A 138, 313-319 (2004)

199. M. A. Verde, C. Barriga-Montoya and B. Fuentes-Pardo: Pigment dispersing hormone generates a circadian response to light in the crayfish, Procambarus clarkii. Comp Biochem Physiol A 147, 983-992 (2007)

200. P. Fernlund: Chromactivating hormones of Pandalus borealis: isolation and purification of a light-adapting hormone. Biochim Biophys Acta 237, 519-529 (1971)

201. P. Fernlund: Structure of a light-adapting hormone from the shrimp Pandalus borealis. Biochim Biophys Acta 439, 17-25 (1976)

202. K. R. Rao, J. P. Riehm, C. A. Zahnow, L. H. Kleinholz, G. E. Tarr, L. Johnson, S. Norton, M. Landau, O. J. Semmes, R. M. Sattelberg, W. H. Jorenby and M. F. Hintz: Characterization of a pigment-dispersing hormone in eyestalks of the fiddler crab Uca pugilator. Proc Natl Acad Sci USA. 82, 5319-5322 (1985)

203. K. R. Rao and J. P. Riehm: Pigment-dispersing hormones: a novel family of neuropeptides from arthropods. Peptides 9 , $153-159$ (1988)

204. K. R. Rao: Crustacean pigment-dispersing hormones: chemistry, distribution and actions. Pigment Cell Res 2, 266-270 (1992)

205. K. R. Rao and J. P. Riehm: Pigment-dispersing hormones. Ann N Y Acad Sci 680, 78-88 (1993)

206. J. M. Klein, C. J. Mohrherr, F. Sleutels, J. P. Riehm and K. R. Rao: Molecular cloning of two pigment-dispersing hormone (PDH) precursors in the blue crab Callinectes sapidus reveals a novel member of the PDH neuropeptide family. Biochem Biophys Res Commun 205, 410-416 (1994)

207. Q. Fu, L. S. Tang, E. Marder and L. Li: Mass spectrometric characterization and physiological actions of VPNDWAHFRGSWamide, a novel B type allatostatin in the crab, Cancer borealis. J Neurochem. 101, 1099-1107. (2007)

208. M. Ma, J. Wang, R. Chen and L. Li: Expanding the Crustacean neuropeptidome using a multifaceted mass spectrometric approach. J Proteome Res 8, 2426-2437. (2009)

209. T. Ohira, H. Katayama, S. Tominaga, T. Takasuka, T. Nakatsuji, H. Sonobe, K. Aida and H. Nagasawa: Cloning and characterization of a molt-inhibiting hormone-like peptide from the prawn Marsupenaeus japonicus. Peptides 26, 259-268 (2005)

210. T. Ohira, N. Tsutsui, I. Kawazoe and M. N. Wilder: Isolation and characterization of two pigment-dispersing hormones from the whiteleg shrimp, Litopenaeus vannamei. Zool Sci 23, 601-606 (2006)

211. P. Bulau, I. Meisen, T. Schmitz, R. Keller and J. Peter-Katalinic: Identification of neuropeptides from the sinus gland of the crayfish Orconectes limosus using nanoscale on-line liquid chromatography tandem mass spectrometry. Mol Cell Proteomics 3 , 558-564 (2004)

212. C. Helfrich-Förster: The period clock gene is expressed in CNS neurons which also produce a neuropeptide that reveals the projections of circadian pacemaker cells within the brain of Drosophila melanogaster. Proc Natl Acad Sci USA 92, 612-616 (1995)

213. C. Helfrich-Förster: Neuropeptide PDF plays multiple roles in the circadian clock of Drosophila melanogaster. Sleep Biol Rhythms 7, 130-143 (2009)

214. T. Yoshii, C. Wülbeck, H. Sehadova, S. Veleri, S. Bichler, R. Stanewsky and C. Helfrich-Förster: The neuropeptide pigment-dispersing factor adjusts period and phase of Drosophila`s clock. J Neurosci 29, 2597-2610 (2009) 
215. U. Homberg, S. Würden, H. Dircksen and K. R. Rao: Comparative anatomy of pigment-dispersing hormoneimmunoreactive neurons in the brain of orthopteroid insects. Cell Tissue Res 266, 343-357 (1991)

216. T. Reischig and M. Stengl: Morphology and pigment-dispersing hormone immunocytochemistry of the accessory medulla, the presumptive circadian pacemaker of the cockroach Leucophaea maderae: A light- and electron-microscopic study. Cell Tissue Res 285, 305-319 (1996)

217. E. Moreno-Sáenz, J. Hernández-Falcón and B. Fuentes-Pardo: Role of the sinus gland in crayfish circadian rhythmicity. II. ERG circadian rhythm. Comp Biochem Physiol A 87, 119-125 (1987)

218. T. Aoto: Diurnal variation in chromatophorotropic potency of the neurosecretory system of the freshwater prawn Palaemon paucidens. J Fac Sci Hokkaido Univ Ser VI Zool 16, 113-120 (1966)

219. H. Aréchiga and F. Mena: Circadian variations in hormone content in the nervous system of crayfish. Comp Biochem Physiol 52A, 581-584 (1975)

220. M. Fingerman: Circadian rhythm of distal retinal pigment migration in the fiddler crab, Uca pugilator, maintained in constant darkness and its endocrine control. Biol Rhythm Res 1, 115-121 (1970)

221. T. Aoto and S. Hisano: Ultrastructural evidence for the existence of the distal retinal pigment light-adapting hormone in the sinus gland of the prawn Palaemon paucidens. Gen Comp Endocrinol 60, 468-474 (1985)

222. B. Petri and M. Stengl: Pigment-dispersing hormone shifts the phase of the circadian pacemaker of the cockroach Leucophaea maderae. J Neurosci 17, 4087-4093 (1997)

223. C. Helfrich-Förster, M. Täuber, J. H. Park, M. Mühlig-Versen, S. Schneuwly and A. Hofbauer: Ectopic expression of the neuropeptide pigment-dispersing factor alters behavioral rhythms in Drosophila melanogaster. J Neurosci 20, 3339-3353 (2000)

224. B. Fuentes-Pardo and M. C. Garcia: Effect of light deprivation on the neurohumoral activity of the visual system of the crayfish. Comp Biochem Physiol 64A, 549-555 (1979)

225. D. R. Nässel, S. Shiga, E. M. Wikstrand and K. R. Rao: Pigment-dispersing hormone-immunoreactive neurons and their relation to serotonergic neurons in the blowfly and cockroach visual system. Cell Tissue Res 266, 511-523 (1991)

226. C. Helfrich-Förster: Pigment-dispersing hormone-immunoreactive neurons in the nervous system of wild-type Drosophila melanogaster and of several mutants with altered circadian rhythmicity. J Comp Neurol 337, 177-190 (1993)

227. U. Homberg, T. Reischig and M. Stengl: Neural organization of the circadian system of the cockroach Leucophaea maderae. Chronobiol Int 20, 577-591 (2003)

228. T. Reischig, B. Petri and M. Stengl: Pigment-dispersing hormone (PDH)-immunoreactive neurons form a direct coupling pathway between the bilaterally symmetric circadian pacemakers of the cockroach Leucophaea maderae. Cell Tissue Res 318 , 553-564 (2004)

229. S. Mangerich, R. Keller, H. Dircksen, K. R. Rao and J. P. Riehm: Localization of piment-dispersing hormone (PDH) and coexistence with FMRFamide immunoreactivity in the eyestalks of two decapod crustaceans. Cell Tissue Res 250, 365-375 (1987)

230. J. Strauss, Q. Zhang, P. Verleyen, J. Huybrechts, K. Pauels and H. Dircksen: Multiple identified peptidergic interneurons express a novel pigment-dispersing hormone in the Daphnia brain and visual ganglia, some showing evidence for clock-neuron function. Comp Biochem Physiol A 153, S156-S157 (2009)

231. K. R. Rao and M. Fingerman: Action of biogenic amines on crustacean chromatophores. II. Analysis of erythrophores in the fiddler crab, Uca pugilator, to indolealkylamines and an eyestalk hormone. Comp Gen Pharmacol 1, 117-126 (1970)

232. K. R. Rao and M. Fingerman: Color changes induced by certain indole alkaloids in the fiddler crab, Uca. Comp Biochem Physiol C 51, 59-62 (1975)

233. K. R. Rao and M. Fingerman: Regulation of release and mode of action of crustacean chromatophorotropins. Amer Zool 23, 517-527 (1983) 
234. T. L. Page and J. L. Larimer: Extraretinal photoreceptors in entrainment of crustacean circadian rhythms. Photochem Photobiol 23, 245-251 (1976)

235. M. Miranda-Anaya and M. L. Fanjul-Moles: Non-parametric effects of monochromatic light on the activity rhythm of juvenile crayfish. Chronobiol Int 14, 24-34 (1997)

236. B. S. Beltz and E. A. Kravitz: Mapping of serotonin-like immunoreactivity in the lobster nervous system. J Neurosci 3, 585$602(1983)$

237. C. Bellon-Humbert and F. van Herp: Localization of serotonin-like immunoreactivity in the eyestalk of the prawn Palaemon serratus (Crustacea, Decapoda, Natantia). J Morphol 196, 307-320 (1988)

238. D. Real and G. Czternasty: Mapping of serotonin-like immunoreactivity in the ventral nerve cord of crayfish. Brain Res 521, 203-212 (1990)

239. B. S. Beltz: Distribution and functional anatomy of amine-containing neurons in decapod crustaceans. Microsc Res Tech 44 , $105-120$ (1999)

240. S.-R. Yeh, R. A. Fricke and D. H. Edwards: The effect of social experience on serotonergic modulation of the escape circuit of crayfish. Science 271, 366-369 (1996)

241. E. A. Kravitz: Serotonin and aggression: insights gained from a lobster model system and speculations on the role of amine neurons in a complex behavior. J Comp Physiol A 186, 221-238 (2000)

242. E. A. Kravitz and R. Huber: Aggression in invertebrates. Curr Opin Neurobiol 13, 736-743 (2003)

243. A. J. Farca-Luna, J. I. Hurtado-Zavala, T. Reischig and R. Heinrich: Circadian regulation of agonistic behavior in groups of parthenogenetic marbled crayfish, Procambarus sp.. J Biol Rhythms 24, 64-72 (2009)

244. B. Zhang and R. M. Harris-Warrick: Multiple receptors mediate the modulatory effects of serotonergic neurons in a small neural network. J Exp Biol 190, 55-77 (1994)

245. D. H. Edwards and N. Spitzer: Social dominance and serotonin receptor genes in crayfish. Curr Top Dev Biol 74, 177-179 (2006)

246. M. A. Sosa, N. Spitzer, D. H. Edwards and D. J. Baro: A crustacean serotonin receptor: cloning and distribution in the thoracic ganglia of crayfish and freshwater prawn. J Comp Neurol 473, 526-537 (2004)

247. M. C. Clark, T. E. Dever, J. J. Dever, P. Xu, V. Rehder, M. A. Sosa and D. J. Baro: Arthropod 5-HT2 receptors: a neurohormonal receptor in decapod crustaceans that displays agonist independent activity resulting from an evolutionary alteration to the DRY motif. J Neurosci 24, 3421-3435 (2004)

248. O. Castanon-Cervantes, B.-A. Battelle and M. L. Fanjul-Moles: Rhythmic changes in the serotonin content of the brain and eyestalk of crayfish during development. J Exp Biol 202, 2823-2830 (1999)

249. M. Wildt, E. M. Goergen, J. L. Benton, D. C. Sandeman and B. Beltz: Regulation of serotonin levels by multiple lightentrainable endogenous rhythms. J Exp Biol 207, 3765-3774 (2004)

250. E. G. Escamilla-Chimal, C. C. Garcia-Rivera, M. Aguilar-Morales, V. J. Romero-Diaz and M. L. Fanjul-Moles: The retina of crayfish Procambarus clarkii during development shows serotonin and tryptophan hydroxylase-like immunoreactivity daily changes. Biol Rhythm Res 29, 471-479 (1998)

251. H. Aréchiga, E. Banuelos, E. Frixione, A. Picones and L. Rodriguez-Sosa: Modulation of crayfish retinal sensitivity by 5Hydroxytryptamine. J Exp Biol 150, 123-143 (1990)

252. G. Calderón-Rosete, G. Flores and L. Rodriguez-Sosa: Diurnal rhythm in the levels of the serotonin 5-HT1A receptors in the crayfish eyestalk. Synapse 59, 368-373 (2006)

253. N. Spitzer, B. L. Antonsen and D. H. Edwards: Immunocytochemical mapping and quantification of expression of a putative type 1 serotonin receptor in the crayfish nervous system. J Comp Neurol 484, 261-282 (2005) 
254. C. Y. Lee, S. M. Yau, C. S. Liau and W. J. Huang: Serotonergic regulation of blood glucose levels in the crayfish, Procambarus clarkii: site of action and receptor characterization. J exp Zool 286, 596-605 (2000)

255. C. Y. Lee, P. F. Yang and H. S. Zou: Serotonergic regulation of crustacean hyperglycemic hormone secretion in the crayfish, Procambarus clarkii. Physiol Biochem Zool 74, 376-382 (2001)

256. L. Rodriguez-Sosa, A. Picones, G. Calderon-Rosete, S. Islas and H. Aréchiga: Localization and release of 5hydroxytryptamine in the crayfish eyestalk. J Exp Biol 200, 3067-3077 (1997)

257. R. Hardeland and B. Poeggeler: Non-vertebrate melatonin. J Pineal Res 34, 233-241 (2003)

258. D. X. Tan, R. Hardeland, L. C. Manchester, S. D. Paredes, A. Korkmaz, R. M. Sainz, J. C. Mayo, L. Fuentes-Broto and R. J. Reiter: The changing biological roles of melatonin during evolution: from an antioxidant to signals of darkness, sexual selection and fitness. Biol Rev Camb Philos Soc, in press. Epub, ahead of print (2009)

259. B. Vivien-Roels and P. Pévet: Melatonin: presence and formation in invertebrates. Experientia 49, $642-647$ (1993)

260. A. R. Tilden, P. Rasmussen, R. M. Awantang, S. Furlan, J. Goldstein, M. Palsgrove and A. Sauer: Melatonin cycle in the fiddler crab Uca pugilator and influence of melatonin on limb regeneration. J Pineal Res 23, 142-147 (1997)

261. J. Aguzzi, J. Sanchez-Pardo, J. A. Garcia and F. Sarda: Day-night and depth differences in haemolymph melatonin of the Norway lobster, Nephrops norvegicus (L.). Deep-Sea Res Pt I-Oceanog Res 56, 1894-1905 (2009)

262. M. T. Agapito, B. Herrero, M. I. Pablos, J. L. Miguel and J. M. Recio: Circadian rhythms of melatonin and serotonin- $N$ acetyltransferase activity in Procambarus clarkii. Comp Biochem Physiol A 112, 179-185 (1995)

263. R. Dubbels and R. Elofsson: N-acetylation of arylalkylamines (serotonin and tryptamine) in the crayfish brain. Com Biochem Physiol 93C, 307-312 (1989)

264. B. Withyachumnarnkul, A. Pongsa-Asawapaiboon, S. Ajpru, P. Siamwalla, W. Trakulrungsi and W. Samritthong: Continuous light increases $\mathrm{N}$-acetyltransferase activity in the optic lobe of the giant freshwater prawn Macrobrachium rosenbergii de Man (Crustacea: Decapoda). Life Sci 51, 1479-1484 (1992)

265. B. Withyachumnarnkul, K. Buppaniroj and A. Pongsa-Asawapaiboon: N-acetyltransferase and melatonin levels in the optic lobe of giant fresh-water prawns, Macrobrachium rosenbergii de Man. Comp Biochem Physiol A 102, $703-707$ (1992)

266. I. Balzer, I. R. Espindola and B. Fuentes-Pardo: Daily variations of immunoreactive melatonin in the visual system of crayfish. Biol Cell 89, 539-543 (1997)

267. A. R. Tilden, J. Alt, K. Brummer, R. Groth, K. Herwig, A. Wilson and S. Wilson: Influence of photoperiod on Nacetyltransferase activity and melatonin in the fiddler crab Uca pugilator. Gen Comp Endocrinol 122, 233-237 (2001)

268. F. E. Maciel, M. A. Geihs, M. A. Vargas, B. P. Cruz, B. Padovani Ramos, O. Vakkuri, V. B. Meyer-Rochow, L. E. Maia Nery and S. Allodi: Daily variation of melatonin content in the optic lobes of the crab Neohelice granulata. Comp Biochem Physiol A 149, 162-166 (2008)

269. M. A. Geihs, M. A. Vargas, F. E. Maciel, S. S. Caldas, B. P. Cruz, E. G. Primel, J. M. Monserrat and L. E. Nery: Effect of melatonin in the antioxidant defense system in the locomotor muscles of the estuarine crab Neohelice granulata (Decapoda, Brachyura). Gen Comp Endocrinol 166, $72-82$ (2010)

270. J. Prieto-Sagredo, I. Ricalde-Recchia, M. E. Duran-Lizarraga, M. E. Gonsebatt and M. L. Fanjul-Moles: Changes in hemolymph glutathione status after variation in photoperiod and light-irradiance in crayfish Procambarus clarkii and Procambarus digueti. Photochem Photobiol 71, 487-492 (2000)

271. M. L. Fanjul-Moles, M. E. Duran-Lizarraga, M. E. Gonsebatt and J. Prieto-Sagredo: The effect of photoperiod and light irradiance on the antioxidant circadian system of two species of crayfish from different latitudes: Procambarus clarkii and P. digueti. Photochem Photobiol. 77, 210-218 (2003)

272. M. E. Durán-Lizarraga, J. Prieto-Sagredo, M. E. Gonsebatt and M. L. Fanjul-Moles: Crayfish Procambarus clarkii shows circadian variations in different parameters of the GSH cycle. Photochem Photobiol 74, 350-355 (2001) 
273. M. L. Fanjul-Moles, J. Prieto-Sagredo, D. S. Lopez, R. Bartolo-Orozco and H. Cruz-Rosas: Crayfish Procambarus clarkii retina and nervous system exhibit antioxidant circadian rhythms coupled with metabolic and luminous daily cycles. Photochem Photobiol 85, 78-87 (2009)

274. H. Solis-Chagoyan, L. Mendoza-Vargas and B. Fuentes-Pardo: Melatonin modulates the ERG circadian rhythm in crayfish. Comp Biochem Physiol A 149, 373-379 (2008)

275. L. Mendoza-Vargas, H. Solis-Chagoyan, G. Benitez-King and B. Fuentes-Pardo: MT2-like melatonin receptor modulates amplitude receptor potential in visual cells of crayfish during a 24-hour cycle. Comp Biochem Physiol A 154, 486-492 (2009)

276. H. Aréchiga: Circadian rhythmicity in the nervous system of crustaceans. Fed Proc 36, 89-100 (1977)

277. H. Aréchiga, C. Cabrera-Peralta and A. Huberman: Functional characterization of the neurodepressing hormone in the crayfish. J Neurobiol 10, 409-422 (1979)

278. H. Aréchiga, J. A. Williams, R. S. Pullin and E. Naylor: Cross-sensitivity to neuro-depressing hormone and its effect on locomotor rhythmicity in two different groups of crustaceans. Gen Comp Endocrinol 37, 350-357 (1979)

279. A. Huberman, H. Aréchiga, A. Cimet, J. De La Rosa and C. Aramburo: Isolation and purification of a neurodepressing hormone from the eyestalk of Procambarus bouvieri (Ortmann). Eur J Biochem 99, 203-208 (1979)

280. A. Huberman: Neurodepressing hormone (NDH): fact or fiction? Crustaceana 69, 1-18 (1996)

281. H. Dircksen, P. Skiebe, B. Abel, H. Agricola, K. Buchner, J. E. Muren and D. R. Nässel: Structure, distribution, and biological activity of novel members of the allatostatin family in the crayfish Orconectes limosus. Peptides 20, 695-712 (1999)

282. H. Duve, A. H. Johnsen, J. L. Maestro, A. G. Scott, P. P. Jaros and A. Thorpe: Isolation and identification of multiple neuropeptides of the allatostatin superfamily in the shore crab Carcinus maenas. Eur J Biochem 250, 727-734 (1997)

283. H. Duve, A. H. Johnsen, A. G. Scott and A. Thorpe: Allatostatins of the tiger prawn, Penaeus monodon (Crustacea: Penaeidea). Peptides 23, 1039-1051 (2002)

284. M. Ma, R. Chen, G. L. Sousa, E. K. Bors, M. A. Kwiatkowski, C. C. Goiney, M. F. Goy, A. E. Christie and L. Li: Mass spectral characterization of peptide transmitters/hormones in the nervous system and neuroendocrine organs of the American lobster Homarus americanus. Gen Comp Endocrinol 156, 395-409 (2008)

285. J. R. Mancillas, J. F. McGinty, A. I. Selverston, H. Karten and F. E. Bloom: Immunocytochemical localization of enkephalin and substance $\mathrm{P}$ in retina and eyestalk neurones of lobster. Nature 293, 576-578 (1981)

286. P. P. Jaros, H. Dircksen and R. Keller: Occurrence of immunoreactive enkephalins in a neurohemal organ and other nervous structures in the eyestalk of the shore crab, Carcinus maenas L. (Crustacea, Decapoda). Cell Tissue Res 241, 111-117 (1985)

287. M. Fingerman, M. M. Hanumante, G. K. Kulkarni, R. Ikeda and L. L. Vacca: Localization of substance P-like, leucineenkephalin-like, methionine-enkephalin-like, and FMRFamide-like immunoreactivity in the eyestalk of the fiddler crab, Uca pugilator. Cell Tissue Res 241, 473-477 (1985)

288. H. Dircksen: Fine structure of the neurohemal sinus gland of the shore crab, Carcinus maenas, and immuno-electronmicroscopic identification of neurosecretory endings according to their neuropeptide contents. Cell Tissue Res 269, 249-266 (1992)

289. C. Ollivaux, H. Dircksen, J. Y. Toullec and D. Soyez: Enkephalinergic control of the secretory activity of neurons producing stereoisomers of crustacean hyperglycemic hormone in the eyestalk of the crayfish Orconectes limosus. J Comp Neurol 444, 1-9 (2002)

290. W. Lüschen, F. Buck, A. Willig and P. P. Jaros: Isolation, sequence analysis, and physiological properties of enkephalins in the nervous tissue of the shore crab Carcinus maenas L. Proc Natl Acad Sci USA 88, 8671-8675 (1991)

291. L. A. Wilkens and J. L. Larimer: The CNS photoreceptor of crayfish: morphology and synaptic activity. J comp Physiol 80, 389-407 (1972)

292. L. A. Wilkens: The crayfish caudal photoreceptor: advances and questions after the first half century. Comp Biochem Physiol C 91, 61-68 (1988) 
293. T. W. Simon and D. H. Edwards: Light-evoked walking in crayfish: behavioral and neuronal responses triggered by the caudal photoreceptor. J Comp Physiol A 166, 745-755 (1990)

294. K. Uchizono: The structure of possible photoreceptive elements in the sixth abdominal ganglion of the crayfish. J Cell Biol $15,151-154$ (1962)

295. L. A. Wilkens and J. L. Larimer: Photosensitivity in the sixth abdominal ganglion of decapod crustaceans: a comparative study. J comp Physiol 106, 69-75 (1976)

296. B. Fuentes-Pardo and V. Inclan-Rubio: Caudal photoreceptors synchronize the circadian rhythms in crayfish. I: Synchronization of ERG and locomotor circadian rhythms. Comp Biochem Physiol A 86, 523-527 (1987)

297. D. H. Edwards: Crayfish extraretinal perception I. Behavioural and motoneural response to abdominal illumination. $J$ Exp Biol 109, 291-306 (1984)

298. J. A. Bernal-Moreno, M. Miranda-Anaya and M. L. Fanjul-Moles: Phase shifting of the ERG amplitude circadian rhythm of juvenile crayfish by monochromatic illumination. Biol Rhythm Res 27, 299-301 (1996)

299. L. Rodriguez-Sosa, G. Calderon-Rosete, G. Flores and M. G. Porras: Serotonin-caused phase shift of circadian rhythmicity in a photosensitive neuron. Synapse 61, 801-808 (2007)

300. T. L. Page: Extraretinal photoreception in entrainment and photoperiodism in invertebrates. Experientia 38, 1007-1013 (1982)

301. M. L. Fanjul-Moles, M. Miranda-Anaya and B. Fuentes-Pardo: Effect of monochromatic light upon the ERG circadian rhythm during ontogeny in crayfish Procambarus clarkii. Comp Biochem Physiol A 102, 99-106 (1992)

302. M. Bobkova, P. Grève, V. B. Meyer-Rochow and G. Martin: Description of intracerebral ocelli in two species of North American crayfish: Orconectes limosus (Cambaridae) and Pacifastacus leniusculus (Astacidae). Invert Biol 122, 155-165 (2003)

303. T. L. Page and J. L. Larimer: Neural control of circadian rhythmicity in the crayfish. I. The locomotor rhythm. J comp Physiol 97, 59-80 (1975)

304. R. D. Andrew and A. S. M. Saleuddin: Structure and innervation of a crustacean neurosecretory cell. Can J Zool 56, 423430 (1978)

305. P. P. Jaros and G. Gäde: Evidence for a crustacean hyperglycemic hormone-like molecule in the nervous system of the stick insect, Carausius morosus. Cell Tissue Res 227, 555-562 (1982)

306. H. B. Dowse and J. M. Ringo: Further evidence that the circadian clock in Drosophila is a population of coupled ultradian oscillators. J Biol Rhythms 2, 65-76 (1987)

307. M. Lara-Aparicio, S. López de Medrano, B. Fuentes-Pardo and E. Moreno-Sáenz: A quantitative mathematical model of the ontogeny of a circadian rhythm in crayfish. Bull Math Biol 55, 97-110 (1993)

308. B. Fuentes-Pardo, M. Lara-Aparicio and S. L. De Medrano: On the ontogeny of the motor circadian rhythm in crayfish. Bull Math Biol 63, 353-369 (2001)

309. B. Fuentes-Pardo, A. M. Guzman-Gomez, M. Lara-Aparicio and S. L. de Medrano: A qualitative model of a motor circadian rhythm. Biosystems 71, 61-69 (2003)

310. S. Harzsch: Neurophylogeny: Architecture of the nervous system and a fresh view on arthropod phyologeny. Integr Comp Biol 46, 162-194 (2006)

311. G. Giribet, S. Richter, G. D. Edgecombe and W. C. Wheeler: The position of crustaceans within the Arthropoda - evidence from nine molecular loci and morphology. In: Crustacea and Arthropod Relationships. (Eds.): S. Koenemann and R. A. Jenner. Taylor and Francis, Boca Raton, 307-352 (2005)

312. J. C. Regier, J. W. Shultz and R. E. Kambic: Pancrustacean phylogeny: hexapods are terrestrial crustaceand and maxillipods are not monophyletic. Proc Biol Soc 272, 395-401 (2005) 
313. H. Glenner, P. F. Thomsen, M. B. Hebsgaard, M. V. Sorensen and E. Willerslev: The origin of insects. Science 314, 18831884 (2006)

314. G. E. Budd and M. J. Telford: The origin and evolution of arthropods. Nature 457, 812-817 (2009)

315. S. Koenemann, R. A. Jenner, M. Hoenemann, T. Stemme and B. M. von Reumonz: Arthropod phylogeny revisited, with a focus on crustacean relationships. Arthropod Struct Dev (2009)

316. J. M. Giebultowicz: Molecular mechanism and cellular distribution of insect circadian clocks. Annu Rev Entomol 45, 769793 (2000)

317. H. Sehadova, I. Sauman and F. Sehnal: Immunocytochemical distribution of pigment-dispersing hormone in the cephaic ganglia of polyneopteran insects. Cell Tissue Res 312, 113-125 (2003)

318. C. Helfrich-Förster: Organization of endogenous clocks in insects. Biochem Soc Trans 33, 957-961 (2005)

319. F. Sandrelli, R. Costa, C. P. Kyriacou and E. Rosato: Comparative analysis of circadian clock genes in insects. Insect Mol Biol 17, 447-463 (2008)

320. J. Brady: The physiology of insect circadian rhythms. Adv Insect Physiol 10, 1-115 (1974)

321. J. Blau, F. Blanchard, B. Collins, D. Dahdal, A. Knowles, D. Mizrak and M. Ruben: What is there left to learn about the Drosophila clock? Cold Spring Harb Symp Quant Biol 72, 243-250 (2007)

322. Y. Lin, G. D. Stormo and P. H. Taghert: The neuropeptide pigment-dispersing factor coordinates pacemaker interactions in the Drosophila circadian system. J Neurosci 24, $7951-7957$ (2004)

323. P. H. Taghert: How does the circadian clock send timing information to the brain? Semin Cell Dev Biol 12, 329-341 (2001)

324. T. Yoshii, T. Todo, C. Wülbeck, R. Stanewsky and C. Helfrich-Förster: Cryptochrome is present in the compound eyes and a subset of Drosophila`s clock neurons. J Comp Neurol 508, 952-966 (2008)

325. D. R. Nässel, S. Shiga, C. J. Mohrherr and K. R. Rao: Pigment-dispersing hormone-like peptide in the nervous system of the flies Phormia and Drosophila: immunocytochemistry and partial characterization. J Comp Neurol 331, 183-198 (1993)

326. G. J. Harris and E. Morgan: The location of circa-tidal pacemakers in the estuarine amphipod Corophium volutator using a selective chilling technique. J Exp Biol 110, 125-142 (1984)

327. M. Saigusa: The circa-tidal rhythm of larval release in the incubating crab Sesarma. J Comp Physiol A 159, 21-31 (1986)

328. M. W. Young and S. A. Kay: Time zones: a comparative genetics of circadian clocks. Nature Rev Genet 2, $702-715$ (2001)

329. P. E. Hardin: The circadian timekeeping system of Drosophila. Curr Biol 15, R714-R722 (2005)

330. J.-S. Yang, Z.-M. Dai, F. Yang and W.-J. Yang: Molecular cloning of Clock cDNA from the prawn, Macrobrachium rosenbergii. Brain Res 1067, 13-24 (2006)

331. P. Reddy, W. A. Zehring, D. A. Wheeler, V. Pirrotta, C. Hadfield, J. C. Hall and M. Rosbash: Molecular analysis of the period locus in Drosophila melanogaster and identification of a transcript involved in biological rhythms. Cell 38, 701-710 (1984)

332. J. Landskron, K. F. Chen, E. Wolf and R. Stanewsky: A role for the PERIOD:PERIOD homodimer in the Drosophila circadian clock. PLoS Biol 7, e1000003 (2009)

333. R. J. Konopka: Genetics of biological rhtyhms in Drosophila. Annu Rev Genet 21, 227-236 (1987)

334. J. C. Hall and M. Rosbash: Mutations and molecules influencing biological rhythms. Annu Rev Neurosci 11, 373-393 (1988)

335. P. Emery, R. Stanewsky, C. Helfrich-Förster, M. Emery-Le, J. C. Hall and M. Rosbash: Drosophila CRY is a deep brain circadian photoreceptor. Neuron 26, 493-504 (2000) 
336. M. F. Ceriani, T. K. Darlington, D. Staknis, P. Mas, A. A. Petti, C. J. Weitz and S. A. Kay: Light-dependent sequestration of TIMELESS by CRYPTOCHROME. Science 285, 553-556 (1999)

337. P. Emery, W. So, M. Kaneko, J. C. Hall and M. Rosbash: CRY, a Drosophila clock and light-regulated cryptochrome, is a major contributor to circadian rhythm resetting and photosensitivity. Cell 95, 669-679 (1998)

338. D. Sandeman, R. Sandeman, C. Derby and M. Schmidt: Morphology of the brain of crayfish, crabs, and spiny lobsters - a common nomenclature for homologous structures. Biol Bull 183, 304-326 (1992)

339. M. L. Fanjul-Moles, E. G. Escamilla-Chimal, A. Gloria-Osorio and G. Hernandez-Herrera: The crayfish Procambarus clarkii CRY shows daily and circadian variation. J Exp Biol 207, 1453-1460 (2004)

340. E. G. Escamilla-Chimal and M. L. Fanjul-Moles: Daily and circadian expression of cryptochrome during the ontogeny of crayfish. Comp Biochem Physiol A 151, 461-470 (2008)

341. J. M. Lugo, Y. Morera, T. Rodriguez, A. Huberman, L. Ramos and M. P. Estrada: Molecular cloning and characterization of the crustacean hyperglycemic hormone cDNA from Litopenaeus schmitti. Functional analysis by double-stranded RNA interference technique. FEBS J 273, 5669-5677 (2006)

342. S. H. Tiu and S. M. Chan: The use of recombinant protein and RNA interference approaches to study the reproductive functions of a gonad-stimulating hormone from the shrimp Metapenaeus ensis. FEBS J 274, 4385-4395 (2007)

343. D. Lloyd and E. L. Rossi: Ultradian rhythms from molecules to mind: a new vision of life. Springer Netherlands, Dordrecht, The Netherlands (2008)

344. J. H. Stillman, J. K. Colbourne, C. E. Lee, N. H. Patel, M. R. Phillips, D. W. Towle, B. D. Eads, G. W. Gelembuik, R. P. Henry, E. A. Johnson, M. E. Pfrender and N. B. Terwilliger: Recent advances in crustacean genomics. Integr Comp Biol 48, 852$868(2008)$

345. S. M. Reppert: The ancestral circadian clock of monarch butterflies: role in time-compensated sun compass orientation. Cold Spring Harb Symp Quant Biol 72, 113-118 (2007)

346. R. B. Forward jr. and K. J. Lohmann: Control of egg hatching in the crab Rhithropanopeus harrisii (Gould). Biol Bull 165, 154-166 (1983)

347. M. Gohar, C. Souty and J. L. Picaud: Diurnal rhythms in the synthesis and release of haemolymph proteins in the crustacean Isopoda, Porcellio dilatatus (Brandt), with special reference to vitellogenin. Reprod Nutr Develop 23, 93-100 (1983)

348. E. M. Goergen, L. A. Bagay, K. Rehm, J. L. Benton and B. Beltz: Circadian control of neurogenesis. J Neurobiol 53, 90-95 (2002)

349. H. O. de la Iglesia, E. M. Rodriguez and R. E. Dezi: Burrow plugging in the crab Uca uruguayensis and its synchronization with photoperiod and tides. Physiol Behav 55, 913-919 (1994)

350. J. Honculada Primavera and J. Lebata: Diel activity patterns in Metapenaeus and Penaeus juveniles. Hydrobiologia 295, 295-302 (1995)

351. J. D. Palmer: Comparative studies of circadian locomotory rhythms in four species of terrestrial crabs. Amer Midland Natural 85, 97-105 (1971)

352. C. G. Quilter and B. G. Williams: Circadian activity rhythms in crayfish Paranephrops zealandicus. J Zool 182, 559-571 (1977)

353. G. Guerao: Locomotor activity patterns and feeding habits in the prawn Palaemon xiphias (Crustacea: Decapoda: Palaemonidae) in Alfacs Bay, Ebro Delta (Northwest Mediterranean). Mar Biol 122, 115-119 (1995)

354. P. K. Bregazzi: Locomotor activity rhythms in Tryphosella kergueleni (Miers) and Cheirimedon femoratus (Pfeffer) (Crustacea, Amphipoda). Brit Antarct Surv Bull 33/34, 17-32 (1973)

355. A. Ugolini: Activity rhythms and orientation in sandhoppers (Crustacea, Amphipoda). Front Biosci 8, $722-732$ (2003) 
356. R. B. Forward jr and T. W. Cronin: Tidal rhythms of activity and phototaxis of an esturine crab larva. Biol Bull 158, 295$303(1980)$

357. D. R. Nässel and T. H. Waterman: Massive diurnally modulated photoreceptor membrane turnover in crab light and dark adaptation. J Comp Physiol A 131, 205-216 (1979)

358. M. Fingerman and Y. Yamamoto: Daily rhythm of melanophore pigment migration in eyestalkless fiddler crabs, Uca pugilator. Crustaceana 12, 303-319 (1967)

359. C. Thurman: Rhythmic physiological color change in crustacea: a review. Comp Biochem Physiol C 91, 171-185 (1988)

360. T. Pollard and J. L. Larimer: Circadian rhythmicity of heart rate in the crayfish, Procambarus clarkii. Comp Biochem Physiol A 57, 221-226 (1977)

361. J. Hernández-Falcón and F. Ramón: The circadian rhythm of cardiac frequency in crayfish: a multioscillator system? Biol Rhythm Res 29, 464-470 (1998)

362. I. J. McGaw and B. R. McMahon: Endogenous rhythms of haemolymph flow and cardiac performance in the crab Cancer magister. J Exp Mar Biol Ecol 224, 127-142 (1998)

363. C. C. Chabot and L. K. Webb: Circadian rhythms of heart rate in freely moving and restrained American lobsters, Homarus americanus. Mar Freshw Behav Physiol 41, 29-41 (2008)

364. A. Tilden, L. McGann, J. Schwartz, A. Bowe and C. Salazar: Effect of melatonin on hemolymph glucose and lactate levels in the fiddler crab Uca pugilator. J exp Zool 290, 379-383 (2001)

365. B. J. Martin and H. J. Ceccaldi: Circadian variation in the free fatty acid level of abdominal muscle of Palaemon serratus (Pennant 1777) Crustacea, Decapoda. C R Seances Soc Biol 171, 608-612 (1977)

366. M. L. Fanjul-Moles, T. Bosques-Tistler, J. Prieto-Sagredo, O. Castanon-Cervantes and L. Fernandez-Rivera-Rio: Effect of variation in photoperiod and light intensity on oxygen consumption, lactate concentration and behavior in crayfish Procambarus clarkii and Procambarus digueti. Comp Biochem Physiol A Mol Integr Physiol 119, 263-269 (1998)

367. M. Fingerman and A. D. Lago: Endogenous twenty-four hour rhythms of locomotor activity and oxygen consumption in the crayfish, Orconectes clypeatus. Amer Midland Natural 58, 383-393 (1957)

368. J. Aguzzi, J. B. Company, F. Sardà and P. Abelló: Circadian oxygen consumption patterns in continental slope Nephrops norvegicus (Decapoda: Nephropidae) in the western Mediterranean. J Crust Biol 23, 749-757 (2003)

369. P. K. Kirby and R. D. Harbaugh: Diurnal patterns of ammonia release in marine and terrestrial isopods. Comp Biochem Physiol A 47, 1313-1321 (1974)

370. J. C. Wright and M. Pena-Peralta: Diel variation in ammonia excretion, glutamine levels, and hydration status in two species of terrestrial isopods. J Comp Physiol B 175, 67-75 (2005)

\begin{abstract}
Abbreviations: Act: activating factor; AKH: adipokinetic hormone; AMC: protocerebral anterior median cluster; bHLH: basic helix-loop-helix domain; BPR: brain photoreceptor; BPN: brain photoreceptor neuropil; CHH: Crustacean hyperglycaemic hormone; CLK: Clock; CNS: central nervous system; CPR: caudal photoreceptor; CRY: Cryptochrome; CYC: Cycle; DBT: Double-time; DD: dark-dark conditions; DP: distal pigment of retinal pigment cells; DRPH = distal retinal pigment hormone: synonymous with PDH; ERG: electroretinogram; FaRP: FMRFamide-related peptide; GABA: gamma-amino butyric acid; 5-HT: 5-hydroxytryptamin or serotonin; ir: immunoreactive; LAH: light-adapting hormone, synonymous with PDH; LCMS: liquid chromatography combined with mass spectrometry; LD: light-dark conditions; $1-\mathrm{LN}_{\mathrm{v}} \mathrm{s}$ : large lateral ventral neurons of Drosophila clock; $\mathrm{LN}_{\mathrm{d}} \mathrm{s}$ : dorsal lateral neurons of Drosophila clock; MIH: moult-inhibiting hormone; MOIH: mandibular organinhibiting hormone; NAS: N-acetyl-serotonin; NAT: N-acetyltransferase; NDH: neurodepressing hormone; OGT: olfactoryglobular tract; OPT-GT: optic-globular tract; PAS: PER-ARNT-SIM protein domain; PER: Period; PDH: pigment dispersing hormone; PO2: second post-embryonic stage of crayfish; POs: pericardial organs; PP: proximal pigment of retinal photoreceptors; RIA: radioimmunoassay; RNAi: RNA-interference; RPCH: red pigment-concentrating hormone; SGG: Shaggy; TIM: Timeless; s-LN ${ }_{\mathrm{v}}$ s: small lateral ventral neurons of Drosophila clock; VNC: ventral nerve cord; XOSG: X-organ-sinus gland system.
\end{abstract}


Key Words: Crustacean, Circadian Rhythm, Ultradian Rhythm, Circadian Clock, Pacemaker, Clock Genes, Period, Cryptochrome, Pigment Migration, Red Pigment Concentrating Hormone, Crustacean Hyperglycaemic Hormone, Pigment Dispersing Hormone, Serotonin, Melatonin, Caudal Photoreceptor, Extraretinal Photoreceptor, Crayfish, Drosophila, Procambarus Clarkii, Cherax Destructor, Carcinus Maenas, X-Organ Sinus Gland System, Review

Send correspondence to: Heinrich Dircksen

Adress: Department of Zoology, Stockholm University, Svante Arrhenius vag 18A, S-10691 Stockholm, Sweden

Tel: 0046-8-164076

Fax: 0046-8-167715

Email: dircksen@zoologi.su.se

Figure 1. Retinal pigment distribution in the ommatidium of dark-adapted (DA) and light-adapted (LA) crayfish. Both proximal pigment ( $\mathrm{pp}$ ) in the photoreceptor cells and distal pigment (dp) in the distal pigment cell change position depending on the illumination. Abbreviations ax: axon of the retinular cell; bm: basement membrane; ct: crystalline tract of crystalline cell; drp: distal reflecting platelets; dp: distal pigment cell; pp: proximal pigment within the photoreceptor cell; rh: rhabdom of the photoreceptor cell; tc: tapetal cell = reflecting pigment cell; adapted with permission from ref (95).

Figure 2. Circadian rhythmicity of the electroretinogram (ERG). (A) Circadian rhythmicity of the ERG of isolated retinae from crayfish Procambarus clarkii persists under constant darkness. ERG amplitude depends on stimulus intensity (bottom box) as well as circadian time. Upper trace of bars gives timing of light and dark phases prior to transfer of the specimen to constant darkness. (B) Coupling of circadian ERG rhythms between left and right eyes in P. clarkii in isolated preparations consisting of eyes, eyestalks, and protocerebrum. Parallel ERG recordings from right (upper ERG trace) and left (lower ERG trace) eye show synchronous circadian changes in ERG amplitude (arbitrary units), providing evidence for a coupling mechanism between the two hemispheres. Abbreviations ERG: Electroretinogram; ES: eyestalk; PC: protocerebrum; R: retina. (A,B) reproduced with permission from ref $(23,78)$, respectively.

Figure 3. Schematic representations of patterns of crustacean hyperglycaemic hormone $(\mathrm{CHH})$ and serotonin $(5$-HT) circadian rhythms. (A) Dynamics of adult XOSG CHH neurosecretion and haemolymph hyperglycaemia during a L/D 12:12hr cycle: 1 $\mathrm{CHH}$-synthesis and beginning of axonal transport, 2 axonal transport to the sinus gland, $3 \mathrm{CHH}$ release into the haemolymph, 4 hyperglycaemia acrophase, 5 smaller $\mathrm{CHH}$ release into the haemolymph, 6 smaller hyperglycaemia; reproduced with permission from ref $(163,186)$. $\mathrm{CHH}(\bullet)$ and serotonin $(5-\mathrm{HT}$; ०) immunoreactivity in the retina of post-embryonic stage two (PO2; B) and juvenile (C) crayfish, and in the XOSGs of the PO2 stage (D), and the juvenile stage (E). Symbol density represents amount of immunoreactivity. DR, distal retina; MR, medial retina; PR, proximal retina; reproduced with permission from ref (103).

Figure 4. PDH-immunoreactive neurons in the embryo of the lobster Homarus americanus. (A) Camera lucida-reconstruction of PDH-ir neurons in the optic ganglia and the brain at $60 \%$ of embryonic development (E60\%). Groups of neuronal somata denoted by letters A-E. PDH-ir neurons located laterally to the medulla externa (groups C, C', C') are presumptive homologues of insect clock neurons. Note the contralateral projections of type $\mathrm{C}$ interneurons from the large tract in the MT through brain commissures (arrow), and the large descending type E interneurons running down the entire VNC. (B) PDH-ir neurons in the optic ganglia and brain at $45 \%$ of embryonic development (E45\%). Note the commissural PDH-ir fibre connections between eyestalks (arrow) located above the oesophageal foramen. Abbreviations AL: accessory lobe; AMD/CG: anterior part of the mandibular neuromere; APN anterior protocerebral neuropil; ES: oesophageal foramen; LG: lamina ganglionaris; Lo: lobula; ME: medulla externa; MT: medulla terminalis; N: nauplius eye; OL: olfactory lobe; PMD: posterior mandibular neuromere; PPN: posterior protocerebral neuropil; PT: protocerebral tract; R: retina; S: medulla satellite neuropil; SG: sinus gland; TC: tritocerebrum; scale bar: $50 \mu \mathrm{m}$; adapted with permission from ref (141).

Figure 5. Schematic summary of known circadian oscillators and their functional correlations in crayfish. Established physiological oscillators or pacemakers (grey circles) exist in the retina, the X-organ sinus gland complex, the caudal photoreceptors (CPRs), and likely the brain, whilst the brain photoreceptor (BPR) is not an oscillator but responsible for lightdriven entrainment of locomotory rhythms, and CPRs affect phase settings; arrows indicate respective effects on locomotion and ERG amplitude. See text for further details. Question mark in the abdominal ganglion refers to a possible oscillator in the ventral nerve cord. Abbreviations BPR: brain photoreceptor; CPR: caudal photoreceptor; R: retina; SG: sinus gland; XO: X-organ. 
Table 1. Systems and/or parameters displaying circadian rhythms in crustaceans

\begin{tabular}{|c|c|c|}
\hline System / parameter & Crustacean / group & Reference \\
\hline \multicolumn{3}{|l|}{ Development } \\
\hline Egg release & Emerita & (194) \\
\hline Hatching & Various decapods & (346) \\
\hline Larval release & Various decapods & $(51)$ \\
\hline Vitellogenin levels & Porcellio & $(347)$ \\
\hline Neurogenesis of olfactory projection neurons & Homarus & $(348)$ \\
\hline Moulting & Homarus & $(9,35)$ \\
\hline \multicolumn{3}{|l|}{ Behaviour } \\
\hline Burrowing & Uca, Penaeus & $(349,350)$ \\
\hline Agonistic behaviour & Procambarus spec. & $(243)$ \\
\hline \multicolumn{3}{|l|}{ Locomotion } \\
\hline Locomotory activity & Various decapods & $(3,26,80,303,351-353)$ \\
\hline Locomotory activity and orientation & Various amphipods & $(354,355)$ \\
\hline Diel vertical migration & e.g. Daphnia & $(48)$ \\
\hline Diel horizontal migration & Mysid crustaceans & $(49)$ \\
\hline Phototaxis & Crab larvae & $(356)$ \\
\hline \multicolumn{3}{|l|}{ Sensory systems } \\
\hline Electroretinogram amplitude & Procambarus & $(23,85)$ \\
\hline Caudal photoreceptor amplitude & Procambarus & $(12)$ \\
\hline Distal retinal pigment position & Various decapods & $(97,220)$ \\
\hline Proximal retinal pigment position & Various decapods & $(96)$ \\
\hline \multicolumn{3}{|l|}{ Neuronal parameters } \\
\hline Photoreceptor rhabdomic membrane turnover & Grapsus, Ocypode & $(357)$ \\
\hline Photoreceptor and spectral sensitivity changes & Cherax, Ligia, Procambarus & $(106-110)$ \\
\hline Spike rate of X-organ neurons & Procambarus & $(179)$ \\
\hline Spontaneous multiunit activity of brain neurons & Procambarus & $(88)$ \\
\hline \multicolumn{3}{|l|}{ Integumental pigmentation } \\
\hline Tegumentary chromatophores & Procambarus, Uca & $(358,359)$ \\
\hline \multicolumn{3}{|l|}{ Vegetative physiological parameters } \\
\hline Heart rate, haemolymph flow and cardiac performance & Homarus, Procambarus, Cancer & $(360-363)$ \\
\hline $\begin{array}{ll}\text { Blood sugar level } \\
\end{array}$ & Various decapods & $(172,173,364)$ \\
\hline \begin{tabular}{|c|}
$\mathrm{CHH}$ level \\
\end{tabular} & Astacus & $(174)$ \\
\hline Free fatty acid level in abdominal muscle & Palaemon & $(365)$ \\
\hline $\begin{array}{ll}\text { Lactate level } \\
\end{array}$ & Uca, Procambarus & $(364,366)$ \\
\hline $\begin{array}{ll} & \text { Oxygen uptake }\end{array}$ & Orconectes, Procambarus & $(79,366-368)$ \\
\hline Diel ammonia excretion and glutamine nitrogen storage & Ligidium, Armadillidium & $(369,370)$ \\
\hline $\begin{array}{ll} & \text { Glutathione level } \\
\end{array}$ & Procambarus & $(270)$ \\
\hline Antioxidant level & Procambarus & $(273)$ \\
\hline Haemolymph protein level/vitellogenin & Porcellio & $(347)$ \\
\hline
\end{tabular}

\section{Running title: Identified circadian clock systems in crustaceans}




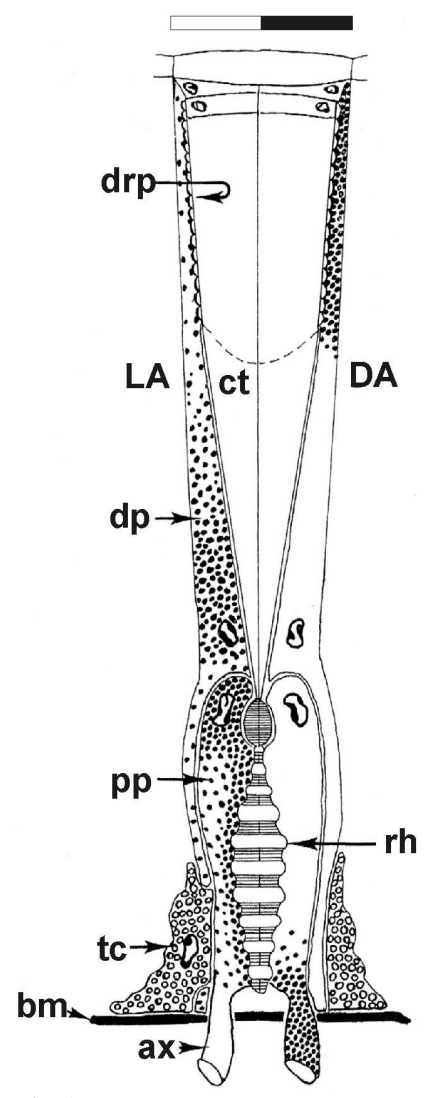

Fig.1 

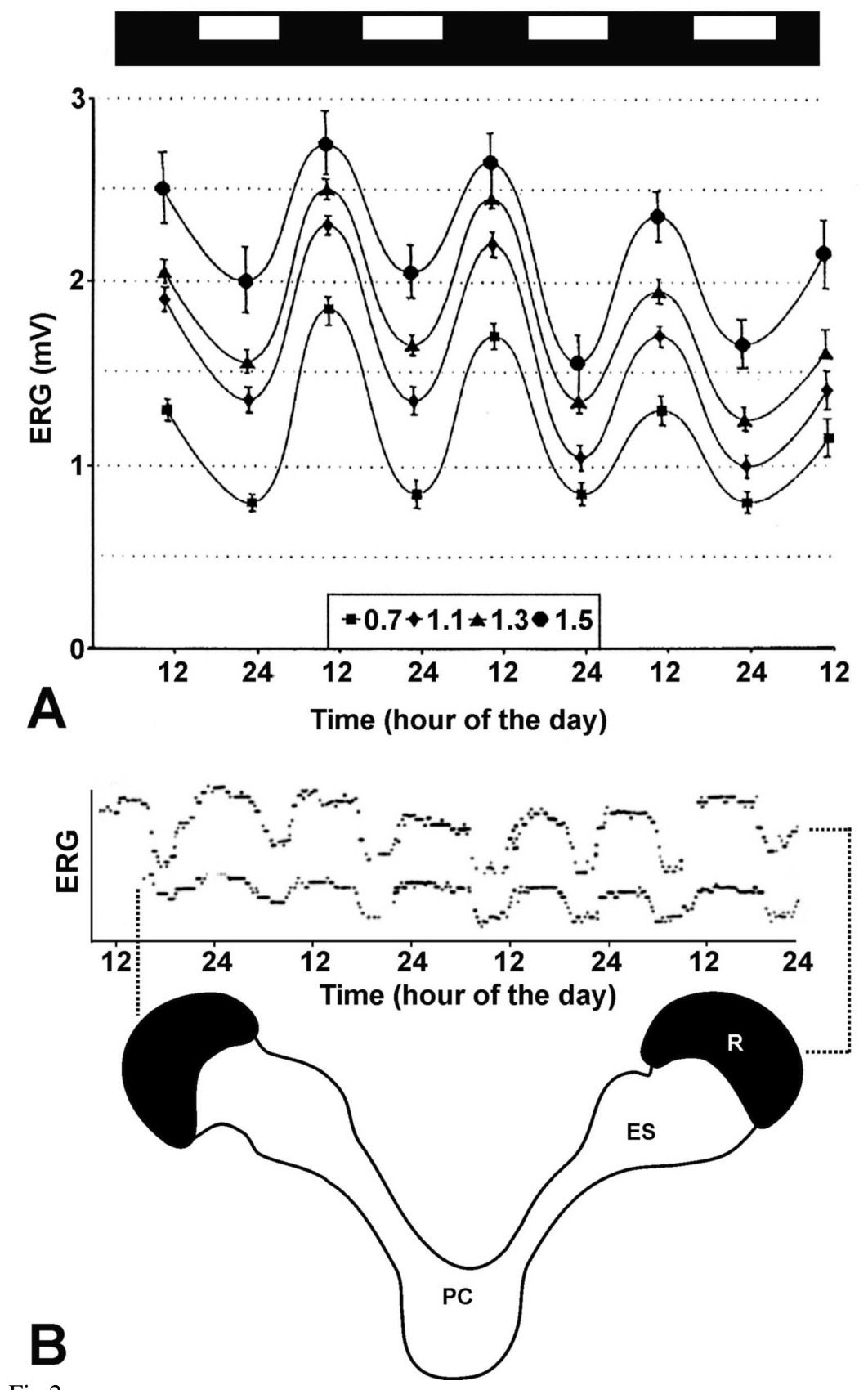

Fig.2 

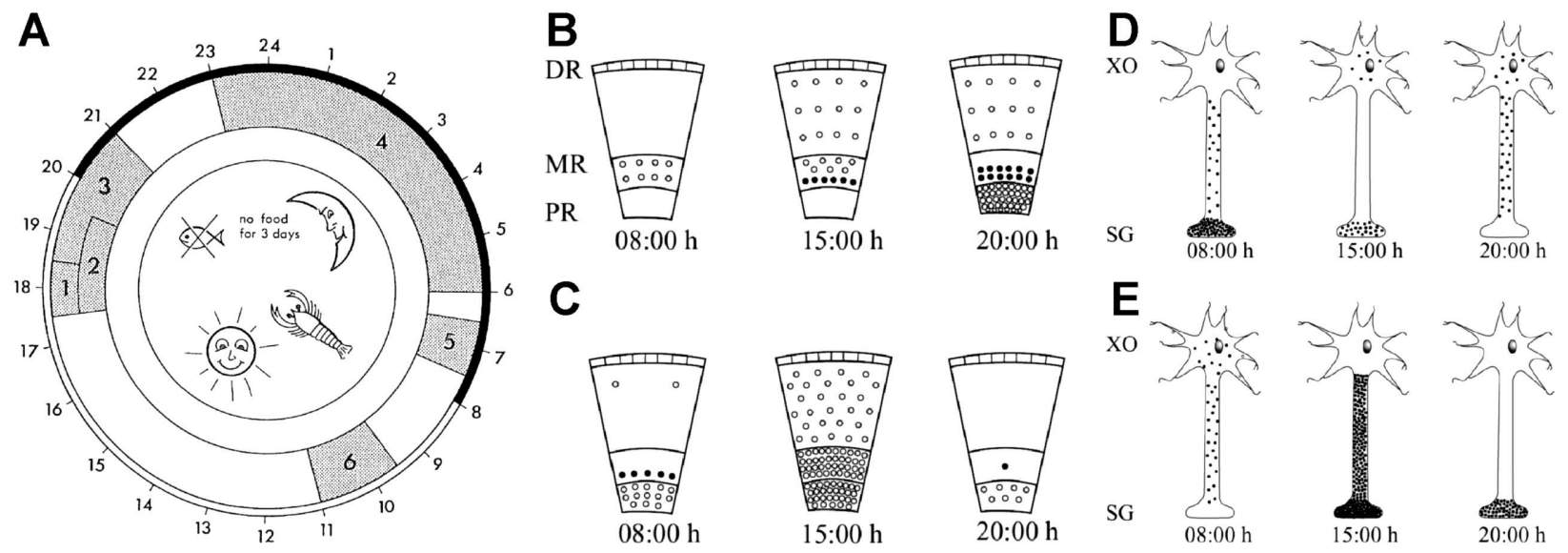

Fig. 3 


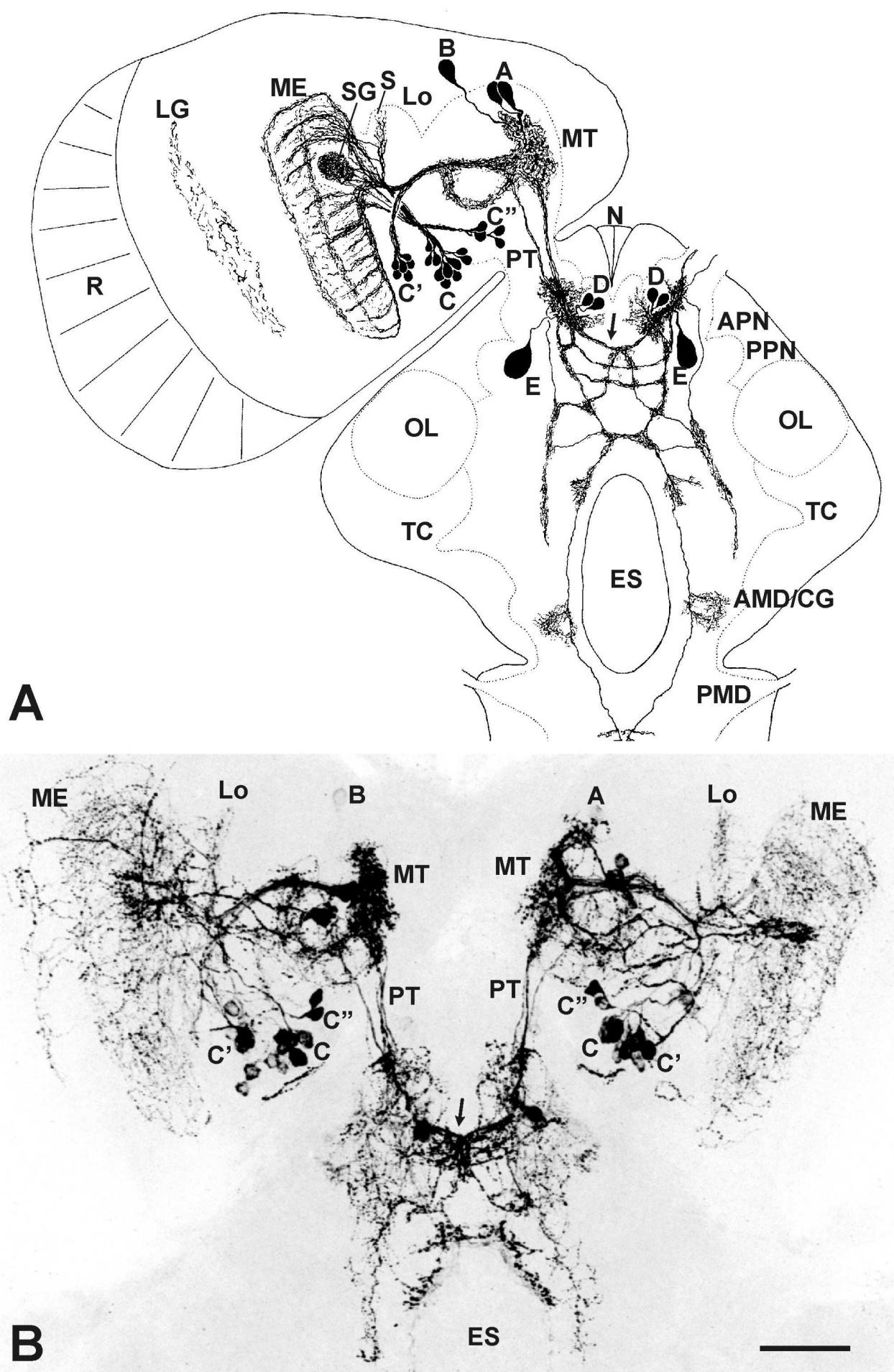

Fig.4 


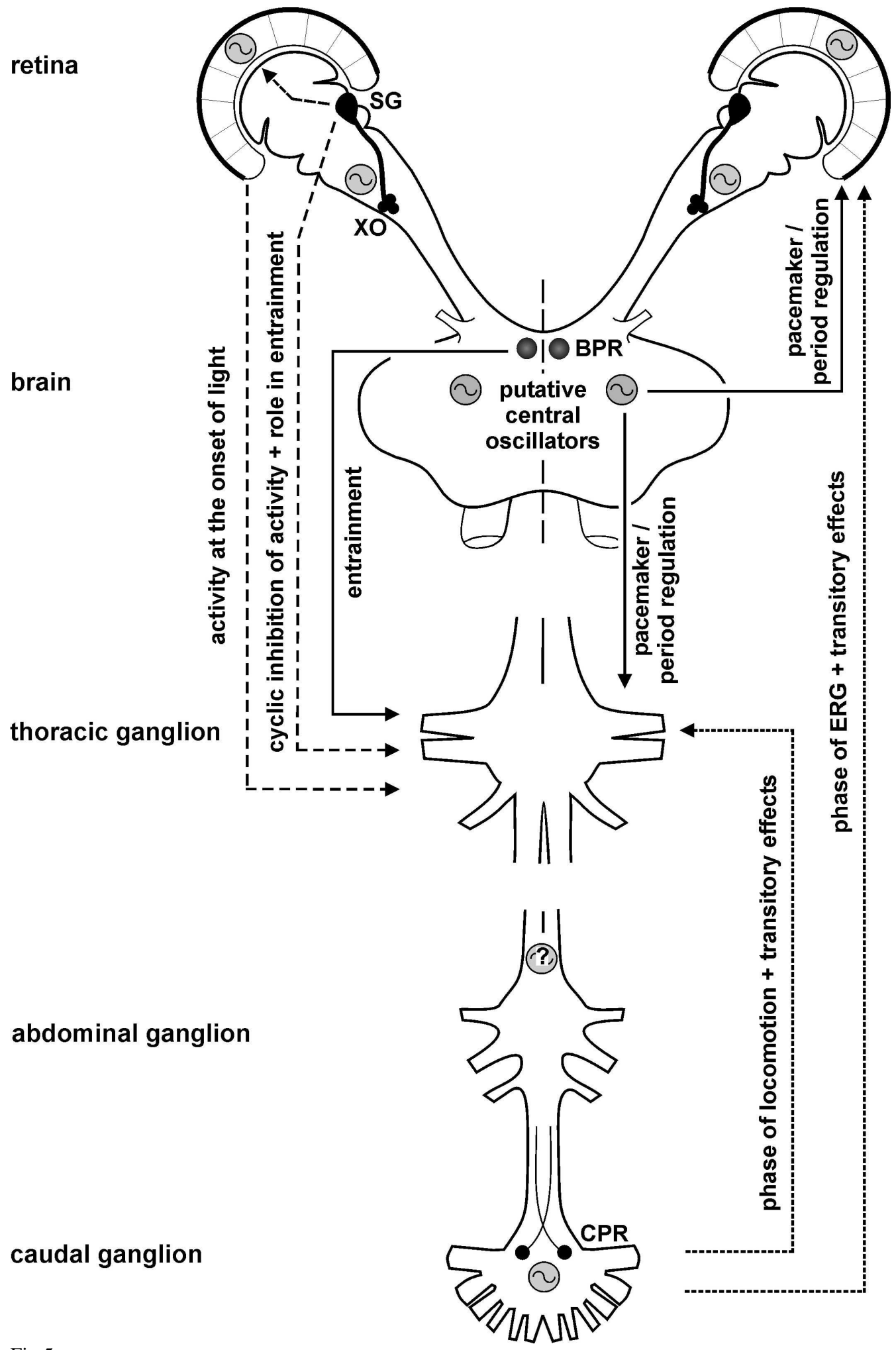

Fig. 5 